\title{
Impedance Spectroscopy Modeling of Lithium Borate with Silica: A Dispersed Ionic Conductor System
}

\author{
Muhammad R. Hasyim ${ }^{\mathrm{a}, \mathrm{b}, \dagger}$, Seth S. Berbano ${ }^{\mathrm{c}, \mathrm{d}}$, Regis M. Cleary ${ }^{\mathrm{e}}$ \\ Michael T. Lanagan ${ }^{\mathrm{a}, \mathrm{c}, \mathrm{d}, \mathrm{f}}$, Dinesh K. Agrawal ${ }^{\mathrm{a}, \mathrm{d}, \mathrm{f}}$
}

a. Department of Engineering Science \& Mechanics

b. Department of Chemical Engineering

c. Center for Dielectrics \& Piezoelectrics, Materials Research Institute

d. Department of Materials Science \& Engineering

e. Facilities Engineering Institute

f. Microwave Processing and Engineering Center, Materials Research Institute

The Pennsylvania State University, University Park, PA 16802 USA

Phone: 814-865-6992, Fax: (814) 865-2326

$\dagger$ Author to whom correspondence should be directed. E-mail: mrh5506@psu.edu

\begin{abstract}
Lithium borate/silica composites, $40 \mathrm{wt} \% \mathrm{SiO}_{2}$ with $\mathrm{x} \cdot \mathrm{Li}_{2} \mathrm{O}+(1-\mathrm{x}) \cdot \mathrm{B}_{2} \mathrm{O}_{3}, \mathrm{x}=0.33,0.50$, were explored with the goal of achieving Li-ion conductivity enhancements across batches with different compositions and processing steps. Two batches were made for each composition, namely micron and nanoscale batches, which differ in their processing and fabrication methods. Phase and microstructural characterization showed a composite which is consisted of a conductor-rich and an insulator-rich region. Previous dispersed ionic conductors, in which conductivity is enhanced by the insulator/conductor interaction, were modeled mostly by percolation models. However, these percolation models are not compatible with conventional impedance spectroscopy circuit models and complex non-linear regression analysis. Hence, new circuit models were created based upon a
\end{abstract}


brick-layer construction that assumed dispersed ionic conductor phenomena to be present. The new circuit models, which are named the theoretical model (TM) and approximation model (AM), uniquely and accurately fitted the impedance spectroscopy data and correctly showed lower resistance and activation energy values for the interfacial conduction pathways. Meanwhile, a typical circuit model which has two parallel RC circuits (2P) showed an anomalous high-frequency M" tail in some samples which does not correspond to the expectations of a realistic and physical modulus data. The combined activation energy and interface activation energy from the new models were compared to literature values of lithium borate conductors and Li-ion dispersed ionic conductors. The comparison results suggested that conductivity of the lithium borate/silica composites can be further enhanced through compositional, microstructural, and phase control.

Keywords: C. Ionic conductivity; dispersed ionic conductors; impedance spectroscopy; equivalent circuit modeling 


\section{Introduction}

Li-ion solid-state conductors are promising replacements for current organic-based liquid electrolytes used in commercial Li-ion batteries. However, the relatively poor ionic conductivity of these solid state electrolytes presents a barrier to successful commercialization. There is a myriad of crystalline structures that are reported to have Li-ion conduction. Some of these include garnettype $\mathrm{Li}_{7} \mathrm{La}_{3} \mathrm{Zr}_{2} \mathrm{O}_{12}$ [1] and $\mathrm{Li}_{5} \mathrm{La}_{3} \mathrm{M}_{2} \mathrm{O}_{12}\left(\mathrm{M}=\mathrm{Nb}\right.$, Ta) [2], thio-LISICON [3], $\mathrm{Li}_{2} \mathrm{~S}-\mathrm{P}_{2} \mathrm{~S}_{5}$ [4], perovskite $\mathrm{La}_{0.5} \mathrm{Li}_{0.5} \mathrm{TiO}_{3}[5,6]$, NASICON[7], $\mathrm{Li}_{1.4} \mathrm{Al}_{0.4} \mathrm{Ge}_{1.6}\left(\mathrm{PO}_{4}\right)_{3}[8]$, and LISICON $\left(\mathrm{Li}_{2+2 \mathrm{x}} \mathrm{Zn}_{1-}\right.$ ${ }_{x} \mathrm{GeO}_{4}$ ) [9]. These materials have unique crystal structures and $\mathrm{Li}$-doping to create the best $\mathrm{Li}$-ion conduction pathways. However, most of these materials have room temperature conductivity values in the range of $10^{-5}-10^{-3} \mathrm{~S} \mathrm{~cm}^{-1}$, which are considerably lower than commercial organic liquid electrolytes, which have conductivity values at the order of $10^{-1}-10^{-2} \mathrm{~S} \mathrm{~cm}^{-1}$ at room temperature. There are superionic conductors that have conductivity values at the order of $10^{-2} \mathrm{~S} \mathrm{~cm}^{-1}$ which rival the commercial liquid electrolytes, such as $\mathrm{Li}_{10} \mathrm{GeP}_{2} \mathrm{~S}_{12}[10], \mathrm{Li}_{10} \mathrm{SnP}_{2} \mathrm{~S}_{12}$ [11], $\mathrm{Li}_{10} \mathrm{Si}_{2} \mathrm{PS}_{12}$ [12], and $\mathrm{Li}_{9.54} \mathrm{Si}_{1.74} \mathrm{P}_{1.44} \mathrm{~S}_{11.7} \mathrm{Cl}_{0.3}[13]$.

Dispersed ionic conductors are composite conductors made from conducting and insulating constituents. The unique property of these dispersed ionic conductors is the formation of space charge regions at the interfaces of the grains between the conductor and insulator. Specifically for insulating constituents, these regions promote the formation of vacancies or interstitials by attracting the mobile ions, effectively changing the concentration profiles of the conducting species and thus creating fast conduction pathways near the interface [14]. When given the optimized volume fraction and phase distribution of an insulating phase, the result is a conduction enhancement by orders of magnitude. The very first reported dispersed ionic conductor was a lithium-based system, a LiI- $\mathrm{Al}_{2} \mathrm{O}_{3}$ composite reporting an order of magnitude higher conductivity at 
$25{ }^{\circ} \mathrm{C}$ and Arrhenius behavior within a temperature range of $-40{ }^{\circ} \mathrm{C}$ to $100{ }^{\circ} \mathrm{C}$ [15]. Other systems including $\mathrm{AgI}-\mathrm{Al}_{2} \mathrm{O}_{3}\left(0-40 \mathrm{~mol} \%\right.$ of $\left.\mathrm{Al}_{2} \mathrm{O}_{3}, 25-150{ }^{\circ} \mathrm{C}\right)$ [16], $\mathrm{CuCl}-\mathrm{Al}_{2} \mathrm{O}_{3}\left(0-30 \mathrm{~mol} \%\right.$ of $\mathrm{Al}_{2} \mathrm{O}_{3}, 25$ - $400{ }^{\circ} \mathrm{C}$ ) [17], and $\mathrm{CaF}_{2}-\mathrm{Al}_{2} \mathrm{O}_{3} / \mathrm{BaF}_{2}-\mathrm{Al}_{2} \mathrm{O}_{3}\left(0-40 \mathrm{~mol} \%\right.$ of $\mathrm{Al}_{2} \mathrm{O}_{3}$, measured at $\left.500{ }^{\circ} \mathrm{C}\right)$ [18], were reported to have Arrhenius behavior and conductivity enhancements up to two orders of magnitude. The list of these dispersed ionic conductors and other composite systems can be exhaustive and extensive reviews, as well as a list of composite ionic conductors, can be found elsewhere [19,20].

More recently, the concept behind dispersed ionic conductors and space charge regions is being applied to nanocrystalline conductors and multi-component oxides/insulator composites. An example of a $\mathrm{Li}$-ion composite nanocrystalline conductor is the $\mathrm{Li}_{2} \mathrm{O}-\mathrm{B}_{2} \mathrm{O}_{3}$ system [21,22], in which both $\mathrm{Li}_{2} \mathrm{O}$ and $\mathrm{B}_{2} \mathrm{O}_{3}$ formed two different nanocrystalline phases instead of a single lithium borate phase. A strong functional dependence for its conductivity was found for $\mathrm{B}_{2} \mathrm{O}_{3}$ composition and grain size, a consequence of increased defects in the interface. In a study of multi-component oxides/insulator composites, silica was added from 0-6 vol\% as an insulating phase to the perovskite $\mathrm{La}_{0.5} \mathrm{Li}_{0.5} \mathrm{TiO}_{3}$ phase [23], and a blocking effect was observed since the optimal silica concentration was not reached. Another dispersed ionic conductor with a multi-component oxide is $\mathrm{Li}_{2} \mathrm{SO}_{4}-\mathrm{Al}_{2} \mathrm{O}_{3}$, where both proton and $\mathrm{Li}$-ion conduction exist, contributing to a conductivity of $10^{-2}$ $\mathrm{S} \mathrm{cm}^{-1}$ at $500{ }^{\circ} \mathrm{C}[24]$.

In this work, a lithium borate, $\mathrm{x} \cdot \mathrm{Li}_{2} \mathrm{O}+(1-\mathrm{x}) \cdot \mathrm{B}_{2} \mathrm{O}_{3}(\mathrm{x}=0.5,0.33)-\mathrm{SiO}_{2}$ system was synthesized, which shall be denoted as lithium borate/silica composites. Alternative conductivity modeling approaches are also explored to study these lithium borate/silica composites. Previous models focused more on describing the trends between total conductivity with the amount of insulator constituent, with percolation models standing as the primary type of models to explain these trends [25-27]. However, crucial information that can be obtained from impedance spectroscopy was not included, where contributions of different phases may be further elucidated. 
Hence, this work focuses on equivalent circuit models that seek to use impedance spectroscopy to yield resistor and capacitance values that provide insight to the ionic conduction mechanism(s).

Microstructural and phase characterizations consisting of scanning electron microscopy (SEM), energy dispersive X-ray spectroscopy (EDS) and X-ray diffraction (XRD) were used to confirm the successful synthesis of the lithium borate/silica composites. Consequently, impedance spectroscopy measurements were used to support the newly proposed models based upon two aspects: (1) goodness of fit, (2) uniqueness of the fit, and (3) their ability to reproduce essential results necessary to verify the existence of the dispersed ionic conductor phenomena.

\section{Materials and Methods}

The lithium borate/silica composite materials were synthesized and categorized based upon size reduction processes. There were two distinct batches; the first batch, named micron batch, utilized amorphous fumed silica and a $24 \mathrm{~h}$ ball milling to mix the two powders together while the second batch, named nanoscale batch, sought to reduce the particle size down to submicron-tonanoscale lengths by high-energy planetary milling for $8 \mathrm{hr}$, a method that has shown to increase ionic conductivity by several orders of magnitude [28]. In addition, $20 \mathrm{~nm}$ silica nanopowder was used for the nanoscale batch. Different lithium oxide/boron oxide mole ratios/fractions were also explored. Two mole ratios will be used: $R=1.0$ corresponding to $\mathrm{x}=0.50$, and $R=0.5$ corresponding to $\mathrm{x}=0.33$. The silica constituent was fixed at $40 \mathrm{wt} \%$. In later sections, a sample will be referred to its mole fraction and batch, e.g., $\mathrm{x}=0.50$ nanoscale sample. Table 1 summarizes the different types of samples across the two batches along with the naming conventions for them.

Lithium carbonate (99.998\% Alfa Aesar), boric acid (99.99\% Alfa Aesar), amorphous fumed silica (99.8\% Alfa Aesar), and nano- $\mathrm{SiO}_{\mathrm{x}}$ amorphous $(99.5 \%, \mathrm{x}=1.2$ to 1.6 , Nanostructured and Amorphous Materials, Inc.) were used as obtained. Stoichiometric mixtures of lithium 
carbonate and boric acid were calcined at $700{ }^{\circ} \mathrm{C}$ for $1 \mathrm{~h}$, ramped from room temperature at a rate of $3{ }^{\circ} \mathrm{C} / \mathrm{min}$, yielding a white fluffy powder. The white powder was then ball milled for $24 \mathrm{~h}$, melted at $1000{ }^{\circ} \mathrm{C}$, ramped from room temperature at a rate of $3{ }^{\circ} \mathrm{C} / \mathrm{min}$, and melt-quenched to produce a clear lithium borate glass. The glass was grounded in a mortar and pestle then ball milled for $24 \mathrm{~h}$ to produce a fine amorphous white powder.

For the micron batch, amorphous fumed silica was introduced to the newly synthesized amorphous powder after melting and prior to the $24 \mathrm{~h}$ ball milling. After ball milling, the powder was pressed into a pellet at a pressure of $155 \mathrm{MPa}$ for 5 minutes and $232 \mathrm{MPa}$ for 3 minutes subsequently using a uniaxial press and sintered at $700{ }^{\circ} \mathrm{C}$ for $1 \mathrm{~h}$. Ag thick film paint was painted on the pellets and co-fired in a tube furnace with the pellets at $700{ }^{\circ} \mathrm{C}$ in $\mathrm{Ar}(80 \mathrm{cc} / \mathrm{min})$. For the nanoscale batch, amorphous nanosilica was introduced followed by $8 \mathrm{~h}$ high-energy planetary milling to produce the two-phase mixed powder. These samples followed the same press-and-sinter process and electrode co-firing, with the exception of one sample ( $\mathrm{x}=0.33$ nanoscale-S) which was sintered at a lower temperature $\left(550{ }^{\circ} \mathrm{C}\right.$ for $\left.1 \mathrm{~h}\right)$ and electrodes were sputtered to avoid the hightemperature co-firing process. This special variation was conducted to observe phase-change and re-crystallization effects. Fig. 1 summarizes all the steps required in fabricating the composite material for the two different batches.

Impedance spectroscopy was conducted in a temperature-controlled chamber from $1 \mathrm{MHz}-$ $0.01 \mathrm{~Hz}$ and temperature ranges that varied depending on the samples, typically $200-500{ }^{\circ} \mathrm{C}$. X-ray powder diffraction $(\mathrm{XRD})$ data were obtained using a Ni-filtered $\mathrm{Cu} \mathrm{K} \alpha$ radiation source (PANalytical Empyrean). The $2 \theta$ range was set to be $5-70^{\circ}$ degrees with a step size of $0.0262 \theta / \mathrm{min}$. Scanning electron microscopy (SEM) was utilized (FEI Nova NanoSEM 630 FESEM) and energy dispersive x-ray spectroscopy (EDS) measurements were also conducted to observe phase distribution and identify different elemental concentrations in the samples. For SEM imaging, 
samples were first fractured and prepared inside a non-conductive epoxy resin. The samples would then be polished and coated with iridium to avoid sample charging.

\section{Results and Discussion}

In formulating new equivalent circuit models, careful consideration must be made regarding the microstructure of the material. In particular, deviations from classical impedance plots must be explained carefully through proper choices of circuit elements, each of which has an assigned physical and microstructural meaning to them. Once the material's phase composition and microstructure have been considered, impedance spectroscopy can be used to validate the new equivalent circuit models and quantify the characteristics of the conduction mechanisms. Thus, in Section 3.1, characterization results on phase composition and microstructure are presented to provide evidence that the two-phase microstructure arrangement validated a need for new equivalent circuit models. In Section 3.2, equivalent circuit models are formulated based on the assumption of dispersed ionic conductor starting from a brick-layer physical picture. Afterwards, in Section 3.3, the results from impedance spectroscopy are used to rigorously test the newly-made equivalent circuit models.

\subsection{Phase Characterization and Microstructure}

Fig. 2 shows the X-ray diffraction patterns for samples with $R=0.5$ or $\mathrm{x}=0.33$ for the micron and nanoscale samples. Two separate crystalline phases were identified, lithium tetraborate $\mathrm{Li}_{2} \mathrm{~B}_{4} \mathrm{O}_{7}$ and quartz silica. With these XRD results, it also confirmed that a crystallization process occurred within the composite material, starting from glassy lithium borate and amorphous silica powder. Furthermore, the special sample $(x=0.33$, nanoscale-S) missed quartz silica peaks within its spectra. This evidence suggested further that the silica phase in these composite materials recrystallized during the sintering or the electrode co-firing step. In addition, from previous studies of 
$\mathrm{Li}_{2} \mathrm{O}-\mathrm{B}_{2} \mathrm{O}_{3}$ and $\mathrm{Li}_{2} \mathrm{O}-\mathrm{B}_{2} \mathrm{O}_{3}-\mathrm{SiO}_{2}$ phase diagrams [29,30], provided also in Fig. 3, the $\mathrm{x}=0.33$ composition (weight fractions of 0.400 for $\mathrm{SiO}_{2} ; 0.106$ for $\mathrm{Li}_{2} \mathrm{O} ; 0.494$ for $\mathrm{B}_{2} \mathrm{O}_{3}$ and mole fractions of 0.385 for $\mathrm{SiO}_{2} ; 0.205$ for $\mathrm{Li}_{2} \mathrm{O} ; 0.410$ for $\mathrm{B}_{2} \mathrm{O}_{3}$ ) should be exactly in the binary join of $\mathrm{SiO}_{2}$ and $\mathrm{Li}_{2} \mathrm{O}-2 \mathrm{~B}_{2} \mathrm{O}_{3}\left(\mathrm{LB}_{2}\right)$. Thus, in this particular ratio and/or composition, the phase composition that was sought through non-equilibrium processing matches with the equilibrium phase composition.

Fig. 4 shows $\mathrm{X}$-ray diffraction patterns for samples with $R=1.0$ or $\mathrm{x}=0.50$ for the micron and nanoscale samples. Based on stoichiometry and previous result on $\mathrm{x}=0.33$, samples were expected to contain lithium metaborate $\mathrm{LiBO}_{2}$ and quartz silica phases only. However, peak analysis indicated that multiple phases had been formed. These phases included lithium borates $\left(\mathrm{Li}_{2} \mathrm{~B}_{4} \mathrm{O}_{7}\right.$ and $\left.\mathrm{LiBO}_{2}\right)$, lithium silicates $\left(\mathrm{Li}_{2} \mathrm{Si}_{2} \mathrm{O}_{5}\right.$ and $\left.\mathrm{Li}_{2} \mathrm{SiO}_{3}\right)$ and quartz silica. Referring to the same phase diagram $[29,30]$, the $\mathrm{x}=0.50$ composition (weight fractions 0.400 for $\mathrm{SiO}_{2} ; 0.180$ for $\mathrm{Li}_{2} \mathrm{O} ; 0.420$ for $\mathrm{B}_{2} \mathrm{O}_{3}$ and mole fractions of 0.356 for $\mathrm{SiO}_{2} ; 0.322$ for $\mathrm{Li}_{2} \mathrm{O} ; 0.322$ for $\mathrm{B}_{2} \mathrm{O}_{3}$ ) should be in a phase field with $\mathrm{SiO}_{2}(\mathrm{~S}), \mathrm{Li}_{2} \mathrm{O}-2 \mathrm{SiO}_{2}\left(\mathrm{LS}_{2}\right)$, and $\mathrm{Li}_{2} \mathrm{O}-2 \mathrm{~B}_{2} \mathrm{O}_{3}\left(\mathrm{LB}_{2}\right)$ phases, albeit very close to the binary join of $\mathrm{LS}_{2}$ and $\mathrm{LB}_{2}$. While the non-equilibrium processing methods helped in retaining the lithium metaborate (LB) phase, the higher lithium content of the $\mathrm{x}=0.5$ samples provided a path for reaction with silica, allowing additional lithium silicate $\left(\mathrm{LS}_{2}\right)$ and borate $\left(\mathrm{LB}_{2}\right)$ phases to be observed in the XRD patterns. Furthermore, due to how close the composition is to the binary join, uncertainty in the actual composition provides a possibility that the $\mathrm{x}=0.50$ sample lies in the neighboring phase field with $\mathrm{Li}_{2} \mathrm{O}-\mathrm{SiO}_{2}(\mathrm{LS}), \mathrm{Li}_{2} \mathrm{O}-2 \mathrm{SiO}_{2}\left(\mathrm{LS}_{2}\right)$, and $\mathrm{Li}_{2} \mathrm{O}-2 \mathrm{~B}_{2} \mathrm{O}_{3}\left(\mathrm{LB}_{2}\right)$. This would explain why lithium metasilicate (LS) was observed in the XRD patterns.

It is also worth noting that multiple phases formed despite relatively different processing methods and therefore, to an extent, varying particle sizes. Also, the $\mathrm{x}=0.50$ nanoscale samples are found to be more reactive than the $\mathrm{x}=0.50$ micron samples based on the ratios of main peak intensities between different phases, in particular the silica phase with some lithium borate phases. 
This is consistent with the understanding of reaction kinetics at the interface, where faster and more readily available reaction pathways can be found in samples with higher interfacial area.

Fig. 5 provides the SEM images for micron and nanoscale samples at $\mathrm{x}=0.33$, highlighting their microstructure. Since silicon is the heavier element than boron, the lighter region can be identified as the silica rich phase while the darker regions can be correlated with lithium borate rich phase for both samples. Multiple point EDS measurements in the micron sample, some of which are provided in Fig. 6, also supported this distribution. However, multiple point EDS measurements on the nanoscale sample, some of which are also provided in Fig. 6, did not provide clear elucidation of the elemental distribution. In fact, Fig. 6 provides two point EDS measurements for the nanoscale sample that have identical elemental distributions but located at a dark and light region. The logical explanation for this anomaly is that as a micron technique, the sampling volume of EDS exceeded the volume of the phases in the samples, which occupied regions less than $10 \mu \mathrm{m}$, causing an overlap between different phases during the point EDS measurements of the nanoscale sample.

The amount of volume that these two phases occupy in each sample is very crucial in the subsequent circuit modeling. For micron samples, each phase took in a very large volume and as a consequence, there was less contact surface area between the silica rich phase and the lithium borate rich phase. Furthermore, the uneven distribution also caused some lithium borate rich phases to be completely isolated and immersed in the silica-rich phase. On the other hand, nanoscale samples had a much more homogeneous distribution between the two phases and occupied a much smaller and even volume. Hence, it is expected that nanoscale samples had a higher interfacial area.

\subsection{Circuit Modeling}

As previously mentioned, a significant contribution to the area of dispersed ionic conductors came from the mathematical modeling of enhanced ionic conduction at the 
insulator/conductor interfaces. One study proposed a bond percolation model to explain the unique composition-dependent phenomenon in dispersed ionic conductors [25]. The approach is pragmatic since it did not directly incorporate the previous thermodynamics and defect chemistry arguments, but rather embedded these principles in the bond percolation model. With the bond-percolation approach, expected critical concentrations of interface percolation and the conductor-insulator transition are rigorously computed and accurately predict the conductivity trends in various dispersed ionic conductors, most of them intended for various single-ion conductors. There are two critical concentrations: the interface percolation, where enough interfaces are formed to create unbroken fast-transport pathways, and the conductor-insulator transition, when a large number of insulator particles effectively block ionic conduction in the material. Variations of the percolation model tried to be more realistic by considering grain size effects [26] and continuum or overlapping particle effects [27]. Besides percolation models, there were other models which proposed a random network, such as the AC model [31] and an effective-medium approach [32].

Shown in Fig. 7 is a variation of a classical model that is found in many polycrystalline material studies, which shall be denoted as the $2 \mathrm{P}$ model. In this typical model, one parallel RC circuit refers to the grain contribution and the other refers to the grain boundary contribution. The parameters are grain resistance $R_{g}$, grain boundary resistance $R_{g b}$, grain capacitance $C_{g}$, grain boundary capacitance $C_{g b}$, and grain constant phase element $Q_{g}$. A constant phase element (CPE) is added in parallel to the grain parallel RC circuit to take account the frequency dispersion that persists in many polycrystalline materials. The assignment of the CPE in such a manner is a common procedure [33]. Additionally, this model will serve as a benchmark for the newly proposed circuit models.

There is great evidence that both micron and nanoscale samples are composed of two regions which are conductor-rich and insulator-rich separately. Hence, all of the samples require a 
more involved circuit model where interactions commonly found in a dispersed ionic conductor matter. To develop such circuit model, it is worth explaining the primary assumptions. These primary assumptions rely on the physics that have been already established within the field of dispersed ionic conductors, as well as common conventions in developing circuit models:

- Brick-layer assumption: given that grain size distribution is narrow and the grain shapes are isotropic, a material can be modeled as composed of smaller cubes/squares, representing bulk grains, stacked together uniformly and bordered with their grain boundaries. [34]

- Dispersed ionic conductor assumption: There exist fast-transport ionic conduction regions within the boundaries of a conductor and insulator.

Fig. 8.a shows the brick-layer physical picture. The brick-layer physical picture represents a 2D brick layer model that has two different phases randomly scattered but follows the specified composition being used (40 wt\%). It is worth noting that Fig. 8.a is very similar to the realizations of percolation models mentioned previously, especially regarding the lattice-like pictures that the percolation model proposes. The difference between the brick-layer physical picture and the percolation models is that the physical picture explicitly differentiate the boundaries into both interface pathways and amorphous boundaries, that act as a third phase that contributes to overall conductivity process.

Like circuit models derived from the brick-layer model, the series and parallel configuration of the brick-layer physical picture will be considered, denoting two pathways for charge carriers to move through the microstructure [34]. In the conventional brick layer model, the series configuration often refers to both grain (squares) and grain boundary (adjacent, left-right boundaries) components connected in series. In this particular brick-layer physical picture, the construction has a fundamental difference. With a two-phase composition, there are now three different kinds of boundaries: conductor-conductor, insulator-insulator, and conductor-insulator. 
There are also two types of grains: conductor grains and insulator grains. By the same principle, the series configuration must be represented as five different components connected in series. This is impractical in nonlinear regression analysis, where too many parameters can cause convergence issues and large error values. Hence, only effective boundary and effective grain contributions should be considered. In here, 'effective' refers to a component which is made from the combination of two or more similar components and taken entirely as one entity.

The parallel configuration is unique in that it is purely composed of boundaries and interfaces; the crucial feature in dispersed ionic conductors. A very similar principle to that in percolation models is used. In a percolation model, the critical threshold in which conductivity enhancement is found is when one continuous line network of insulator-conductor boundaries is formed. In the brick-layer physical picture, this is possible but quite unlikely given the current composition. Hence, it is more likely for the interface pathways to be discontinuously broken by the normal amorphous boundaries that no longer contain the insulator-conductor boundaries. The concept of discontinuous conducting pathways can be found in the modeling of impedance spectra of concrete where discontinuous conduction pathways exist due to concrete paste intermediates essentially acting as insulators $[35,36]$.

The analysis of the series and parallel configuration can be transported to the physical circuit model which is shown in Fig. 8.b. 'Physical' refers to how pieces from the brick-layer model, boundaries, and grains, are assembled directly to act as pseudo-circuit components. These pieces are properly assembled in accordance to the previous qualitative analyses on the parallel and series configurations. By having this picture, electrical circuit components can be assigned to each configuration.

Fig. 9.a shows the equivalent circuit for the theoretical model (TM). For the series configuration, there are different circuit elements such as $R_{g}$ acting as the effective grain resistance, 
$R_{g b}$ as the effective grain boundary resistance, $C_{g b}$ as the effective grain boundary capacitance, and $C_{a l l}$ as the overall material's capacitance. Meanwhile, for the parallel configuration, a resistor $R_{\text {int }}$ defined as the interfacial conductor/insulator resistance and a constant phase element $Q_{\text {block }}$ can be found. The reasoning for the particular arrangement of circuit elements will be elaborated in the subsequent paragraphs.

For the series configuration, a ladder topology is adopted instead of the usual series topology adopted in circuit modeling of multi-phase materials. One reason is that ladder topology is very common for slightly more complex ionic conduction mechanisms. For instance, both a ladder network and its generalization, a transmission line, have been used for mixed ionic-electronic conductors to model the contribution of conventional ionic conduction in the grain and grain boundaries as well as the electronic conduction [37,38]. Another reason is because both a ladder topology and series topology can be exchanged mathematically, creating somewhat similar but directly analogous circuit components that have similar roles for both practical and modeling purposes [39].

For the parallel configuration, three RC parallel circuits in series corresponding to the three different interfacial boundaries is the straightforward modeling method. However, this suffers from not being able to capture the characteristic discontinuous conduction pathways expected. Similar to researchers studying concrete [35], this specific conduction process is instead modeled with a resistor in series with a constant phase element. The choice of the constant phase element is necessary since the conduction (represented as the resistor) is not ideally blocked by the amorphous boundaries, but some amount does pass through and contributes to ionic conduction. Since a constant phase element can be interpreted as a non-ideal capacitor, it becomes the choice component to be combined in series with the resistor. 
At first glance, this model is a reasonable circuit model that can be used for nonlinear regression analysis. Furthermore, all seven parameters have assigned microstructural meaning to them, which gives the model a good physical foundation. However, the amount of parameters involved will be problematic during higher temperature measurements required to obtain Arrhenius behavior. In this situation, impedance semicircles shift to a higher frequency region $(>1 \mathrm{MHz})$ outside of the instrument's range and creating incomplete semicircle arcs. When this happens, convergence issues and error values emerge. Hence, simplifications must be made to the TM model in order for Arrhenius behavior to be captured properly.

This simplification can be achieved by ignoring relaxation associated with the effective grain boundary, i.e., removing $C_{g b}$. This exclusion can be made by assuming that the large portion of the relaxation process observed is due to the discontinuous conduction pathways at the interfaces. By removing this component, there will also be a need to combine the effective grain resistor $R_{g}$ and an effective grain boundary resistor $R_{g b}$ into a single resistor $R_{a l l}$. This model shall be referred as the approximation model (AM), as shown in Fig. 9.b.

It is important that the TM and AM models are tested in a rigorous manner, i.e. the TM and AM models uniquely and accurately fit the experimental data. Thus, in the subsequent impedance analysis section, the $2 \mathrm{P}, \mathrm{TM}$, and $\mathrm{AM}$ models were used to fit impedance data of all samples at a selected, moderate temperature $\left(200-300^{\circ} \mathrm{C}\right)$. The classical $2 \mathrm{P}$ model would serve as a benchmark for the new models. Furthermore, the models were simulated at higher and lower frequencies to showcase the full relaxation feature.

Further validation must also come from predicting two other aspects: (1) physically realizable values for common components and (2) proper relations obtained between two values which are consistent with the dispersed ionic conductor assumption. For these relations, two main hypotheses are presented to test against the nonlinear regression results: 
1. Effective grain resistance will be higher than the other resistances at lower

temperatures. In the TM model, this means that $R_{g}>R_{g b}$ and $R_{g}>R_{\text {int }}$. Lower temperatures are specified since it is expected that the conduction pathways have different activation energy, hence a temperature crossover point may exist.

2. The energy barrier or activation energy for conduction in normal grain/grain boundary pathways is higher than those with the insulator-conductor interfaces. This can be shown with the AM model when $E_{\text {all }}>E_{\text {int }}$, where $E_{\text {all }}$ is the combined activation energy and $E_{\text {int }}$ is the interface activation energy for the discontinuous conduction pathways.

Lastly, the AM model will be used to generate Arrhenius plots and obtain activation energy values for the nanoscale and micron samples.

\subsection{Electrical Characterization}

Fig. 10 shows the combined Nyquist, imaginary impedance (-Z") semi-log and imaginary modulus (M") semi-log plot for $\mathrm{x}=0.33$ nanoscale with all three fitted models. Fig. 11 shows the combined plot for $\mathrm{x}=0.50$ micron with all three fitted models. The plots for the rest of the samples $(\mathrm{x}=0.50$ micron and $\mathrm{x}=0.33$ nanoscale $)$ are provided in the Supplementary Material. In all of these figures, the most common feature is a depressed and seemingly asymmetrical single arc. This is counter-intuitive with the understanding of dispersed ionic conductors since these materials exhibit different phases, boundaries, and conduction mechanisms; all of which should provide at least two semicircles that are distinguishable. This contradiction can be resolved by realizing that highly-overlapped relaxation processes can still occur for multi-phase materials, as exemplified in works by Fricke on effective-medium approaches [40,41]. 
Although it looked as if all models fitted the data correctly at first glance, the benchmark $2 \mathrm{P}$ model has some problems attached to it. When simulated to higher frequencies, the $2 \mathrm{P}$ model revealed an anomalous high-frequency $M$ " tail. The $\mathrm{x}=0.33$ nanoscale, shown in Fig. 10, provides the best example of this behavior, as well as $\mathrm{x}=0.33$ micron sample, which can be seen from the Supplementary Material. The $\mathrm{x}=0.50$ micron sample, shown in Fig. 11, and $\mathrm{x}=0.50$ nanoscale sample from the Supplementary Material did not have the same problem although the $2 \mathrm{P}$ model still predicts a slightly asymmetric M" peak, rather than a broad anomalous M" high-frequency tail. The source of this high-frequency tail in the benchmark 2P model can be sourced from badly parametrized values for the bulk constant phase element. While the performance of the $2 \mathrm{P}$ model is very mixed, it should not be completely dismissed on the basis of anomaly in $\mathrm{x}=0.33$ samples, especially since the $2 \mathrm{P}$ model's fitting on $\mathrm{x}=0.50$ samples is still acceptable.

On the other hand, the newly proposed models (TM and AM) can replicate a proper and symmetrical relaxation peak as expected for a modulus data, despite the constant phase element that is present in both models. The successful prediction of the modulus peak and goodness of fit provide much greater confidence to both the TM and AM models and prove one part of the validity of these new models.

The obtained physical parameters corresponding to the 2P, TM, and AM models are compiled in Table 2, 3, and 4 respectively. From these values, it can also be observed that the order of magnitude of the capacitance values agrees with the corresponding microstructural assignment given to them. For example, in $\mathrm{x}=0.33$ nanoscale sample, the $\mathrm{TM}$ model has $C_{\text {all }}=5.62 \pm 0.05 \mathrm{pF}$ while in the AM model, $C_{\text {all }}=5.57 \pm 0.06 \mathrm{pF}$. This is expected since $C_{\text {all }}$ comes originally from the effective grain capacitance, where $10^{-12} \mathrm{~F}$ is expected for grain contributions. The same evidence can be found for the effective grain boundary contribution; the capacitance value $C_{g b}$ were found in the order magnitude of $10^{-10} \mathrm{~F}$, as expected for grain boundaries. 
In addition, the TM model passes the two hypothesis tests proposed in Section 3.2. These two hypotheses will be mentioned briefly again and discussed in detail. The first hypothesis states that the effective grain resistance will be higher than the other resistances at lower temperatures. The evidence comes from Table 3 and Table 4, both of which compile the physical parameters for the TM and AM models respectively. From there, it is very much evident that the grain resistance $R_{g}$ is consistently lower. As an example, $\mathrm{x}=0.33$ nanoscale sample has an effective grain resistance $R_{g}=1.38 \pm 0.02 \mathrm{M} \Omega$ which is larger than the effective grain boundary resistance $R_{g b}=0.25 \pm 0.02$ $\mathrm{M} \Omega$ and the discontinuous conduction pathways resistance $R_{\text {int }}=0.28 \pm 0.02 \mathrm{M} \Omega$.

A reduction of one order of magnitude is quite significant and provides more evidence of the dispersed ionic conductor phenomena in the samples. Suppose that no prior assumption on dispersed ionic conductivity is made, then the resistances associated with the interfaces and grain boundaries are expected to be higher than the grains, which occupies the bigger volume of charge carriers and therefore provides the main action for the conduction. But now with the dispersed ionic conductor assumption, the TM model explicitly represents the faster interfacial conduction pathways, in which their origins rely on thermodynamics, and visualize the interplay of two phases concretely in the form of a consistently lower $R_{\text {int }}$.

The second hypothesis is that the energy barrier or activation energy for conduction in normal grain/grain boundary pathways is higher than those with the insulator-conductor interfaces. In order to prove this, the Arrhenius plots can be used as evidence. Fig. 12.a. shows the Arrhenius plot for the nanoscale samples while Fig. 12.b shows the Arrhenius plot for the micron samples. All samples exhibited lower activation energies for the interfacial insulator/conductor conductivity. Using $\mathrm{x}=0.50$ nanoscale sample as an example, the combined activation energy $E_{\text {all }}=0.92 \pm 0.01$ $\mathrm{eV}$ while the interface activation energy for the discontinuous pathways $E_{\text {int }}=0.40 \pm 0.04 \mathrm{eV}$. Furthermore, the crossover temperature can also be observed, indicating that the regular conduction 
pathway is more dominant at temperatures higher than $\sim 400{ }^{\circ} \mathrm{C}$. Another example can be taken from $\mathrm{x}=0.33$ micron, where the combined activation energy $E_{\text {all }}=1.38 \pm 0.01 \mathrm{eV}$ while the interface activation energy for the discontinuous pathways $E_{\text {int }}=0.46 \pm 0.04 \mathrm{eV}$.

A related evidence for conductivity enhancements can be found in Table 5, which compiled conductivity values for the combined grain and grain boundary conduction $\sigma_{\text {all }}$ and the interfacial conduction $\sigma_{\text {int }}$ at selected temperatures, extracted with the AM model. For $\sigma_{\text {all, }}$ the nanoscale samples exhibit 20 to 45 times better conductivity than the micron samples. The comparison for $\sigma_{\text {int }}$ is also very compelling; the nanoscale samples exhibit 5 to 8 times better interfacial conductivity than the micron samples. This shows that parameters involving grain, grain boundary, and conductor/insulator interface within the newly proposed models can capture the effects of highenergy planetary milling and amorphous nanosilica effectively.

It is important also to compare the activation energy values with current literature values on similar dispersed ionic conductor systems and lithium borate conductors. Table 6 compiles literature values of activation energies and conductivities for Li-ion-containing phases in the lithium borate/silica composites investigated in this work $[42,43]$. It is worth noting that sample preparations made in the Ref. [43] closely resemble this work's preparation (pellet-sized samples, sintering temperature, precursors), making the comparison fair and accurate. In comparison to $E_{\text {all }}$ obtained in this work, these literature values are consistently higher but lower compared to $E_{\text {int }}$. Furthermore, the conductivity values obtained in this work (as seen in Table 4) lie in between the amorphous and crystalline conductivity values for each composition, where the polycrystalline materials have lower conductivities. This brief comparison of the conductivity values and activation energies with corresponding singe-phase studies suggests that that the polycrystalline lithium borate/silica composites made in this work achieved a characteristic that is between the amorphous and crystalline lithium borate for each composition being made. 
Table 7 compiles literature values of activation energies and highest conductivity value in various Li-ion dispersed ionic conductors. The interface activation energy of the discontinuous conduction pathways $E_{\text {int }}$ are comparable with $\mathrm{LiI}-\mathrm{Al}_{2} \mathrm{O}_{3}$ [15], perovskite $\mathrm{Li}_{0.5} \mathrm{La}_{0.5} \mathrm{TiO}_{3}-\mathrm{SiO}_{2}$ [23], and $\mathrm{Li}_{2} \mathrm{MnCl}_{4}-\mathrm{CeO}_{2}[44]$. For the literature values that follow $E_{\text {int }}$, the studies were conducted at a wide range of insulator concentrations. Therefore, an optimal insulator concentration, activation energy, and ionic conductivity were obtained. The exceptions to these are $\mathrm{Li}_{3} \mathrm{PO}_{4}-\mathrm{Al}_{2} \mathrm{O}_{3}$ [45], which is closer to $E_{\text {all }}$, and $\mathrm{Li}_{2} \mathrm{SO}_{4}-\mathrm{Al}_{2} \mathrm{O}_{3}$ [24]. For the study conducted on $\mathrm{Li}_{3} \mathrm{PO}_{4}-\mathrm{Al}_{2} \mathrm{O}_{3}$, only one composition was explored and hence no indication of whether the conductivity enhancement was at its optimum. Furthermore, the conductivity of $\mathrm{Li}_{2} \mathrm{SO}_{4}-\mathrm{Al}_{2} \mathrm{O}_{3}$ in the study was found to be dominated by protons instead, excluding it from comparison with this work's lithium borate/silica composites.

By excluding the exceptions, a trend can be observed where an activation energy closer to $\sim 0.50 \mathrm{eV}$ is correlated with a material at an optimum concentration of insulator. It will then be beneficial to rigorously study lithium borate/silica composites with a wider insulator composition range to observe how activation energy and conductivity changes, and see whether the same correlation to optimal values can be obtained for the lithium borate/silica composites.

\section{Conclusion}

Two-phase materials consisting of $40 \mathrm{wt} \% \mathrm{SiO}_{2}$ with $\mathrm{x} \cdot \mathrm{Li}_{2} \mathrm{O}+(1-\mathrm{x}) \cdot \mathrm{B}_{2} \mathrm{O}_{3,} \mathrm{x}=0.33,0.50$ were successfully synthesized through a multi-step ceramic fabrication process, differentiated based upon the intensity of the milling/particle size reduction process (micron or nanoscale). From phase analysis, samples with $R=0.5$ or $\mathrm{x}=0.33$ closely resemble to the expected composite system while samples with $R=1.0$ or $\mathrm{x}=0.50$ show more complex phase compositions. In addition, the microstructural data showed that the nanoscale samples contain a more homogeneous distribution of phases while the micron samples give a more uneven distribution, with some lithium borate rich phases isolated within the insulating silica-rich phase. 
Fundamental knowledge regarding accurate conduction models is the key to realizing how composite ionic conductors may be used in future Li-ion conducting devices. Supported by the phase and microstructural characterizations, conduction models for composite ionic conductors were derived heuristically based on the theory of dispersed ionic conductors. This process yielded the TM model and its approximation, the AM model, which provided the means to properly analyze impedance spectroscopy data of dispersed/composite ionic conductor systems without the need to use percolation models. Results from impedance spectroscopy based on qualitatively observing the goodness and uniqueness of fit and comparing model parameters consistently proved the power of the new models. It is suspected based upon the model parameters comparisons with literature values of activation energies that the synthesized composite materials can be further optimized through compositional, microstructural, and phase control. Hence, future studies that span different silica weight percent will be crucial in understanding both the model and material better.

\section{Acknowledgements}

Thanks to Penn State Materials Research Institute staff; Amanda Baker, Jeff Long, Steve Perini, Julie Anderson, and Nichole Wonderling. This material is based on work supported by the National Science Foundation (NSF) as part of the CDP (I/UCRC 1361503), NSF GRFP (DGE1255832), NSF-ERC ASSIST (EEC-1160483), 3M Science and Technology Fellowship, and Department of Energy GATE Fellowship (DE-EE0005575). This work contributed to the completion of M. Hasyim's ESM B.S. thesis "Experimental Studies and Modeling of Lithium Borate/Silica Composite Solid Electrolyte." Any opinion, findings, conclusions and/or recommendations expressed are those of the authors and do not necessarily reflect the views of the NSF. 


\section{References}

[1] R. Murugan, V. Thangadurai, W. Weppner, Fast lithium ion conduction in garnet-type $\mathrm{Li}_{7} \mathrm{La}_{3} \mathrm{Zr}_{2} \mathrm{O}_{12}$, Angew. Chem. Int. Ed. Engl. 46 (2007) 7778-7781.

doi:10.1002/anie.200701144.

[2] V. Thangadurai, H. Kaack, W.J.F. Weppner, Novel fast lithium ion conduction in garnettype $\mathrm{Li}_{5} \mathrm{La}_{3} \mathrm{M}_{2} \mathrm{O}_{12}(\mathrm{M}=\mathrm{Nb}, \mathrm{Ta})$, J. Am. Ceram. Soc. 86 (2003) 437-440. doi:10.1111/j.11512916.2003.tb03318.x.

[3] R. Kanno, M. Murayama, Lithium ionic conductor thio-LISICON: the $\mathrm{Li}_{2} \mathrm{~S}-\mathrm{GeS}_{2}-\mathrm{P}_{2} \mathrm{~S}_{5}$ system, J. Electrochem. Soc. 148 (2001) A742. doi:10.1149/1.1379028.

[4] F. Mizuno, A. Hayashi, K. Tadanaga, M. Tatsumisago, New, highly ion-conductive crystals precipitated from $\mathrm{Li}_{2} \mathrm{~S}-\mathrm{P}_{2} \mathrm{~S}_{5}$ glasses, Adv. Mater. 17 (2005) 918-921. doi:10.1002/adma.200401286.

[5] Y. Inaguma, C. Liquan, M. Itoh, T. Nakamura, T. Uchida, H. Ikuta, et al., High ionic conductivity in lithium lanthanum titanate, Solid State Commun. 86 (1993) 689-693. doi:10.1016/0038-1098(93)90841-A.

[6] A. Mei, X.L. Wang, J.L. Lan, Y.C. Feng, H.X. Geng, Y.H. Lin, et al., Role of amorphous boundary layer in enhancing ionic conductivity of lithium-lanthanum-titanate electrolyte, Electrochim. Acta. 55 (2010) 2958-2963. doi:10.1016/j.electacta.2010.01.036.

[7] J. Alamo, Chemistry and properties of solids with the [NZP] skeleton, Solid. State. Ion. 6365 (1993) 547-561. doi:10.1016/0167-2738(93)90158-Y.

[8] H. Aono, E. Sugimoto, Y. Sadaoka, N. Imanaka, G.Y. Adachi, Electrical properties and sinterability of lithium germanium phosphate $\mathrm{Li}_{1+x} \mathrm{M}_{\mathrm{x}} \mathrm{Ge}_{2-\mathrm{x}}\left(\mathrm{PO}_{4}\right)_{3}, \mathrm{M}=\mathrm{Al}, \mathrm{Cr}, \mathrm{Ga}, \mathrm{Fe}, \mathrm{Sc}$, and 
In systems, Bull. Chem. Soc. Jpn. 65 (1992) 2200-2204. doi:10.1246/bcsj.65.2200.

[9] P.G. Bruce, A.R. West, The A-C conductivity of polycrystalline LISICON, $\mathrm{Li}_{2+2 \mathrm{x}} \mathrm{Zn}_{1-\mathrm{x}} \mathrm{GeO}_{4}$, and a model for intergranular constriction resistances, J. Electrochem. Soc. 130 (1983) 662669. doi:10.1149/1.2119778.

[10] N. Kamaya, K. Homma, Y. Yamakawa, M. Hirayama, R. Kanno, M. Yonemura, et al., A lithium superionic conductor., Nat. Mater. 10 (2011) 682-6. doi:10.1038/nmat3066.

[11] P. Bron, S. Johansson, K. Zick, auf der G. Jörn, S. Dehnen, B. Roling, $\operatorname{Li}_{10} \mathrm{SnP}_{2} \mathrm{~S}_{12}$ : An affordable lithium superionic conductor, J. Am. Chem. Soc. 135 (2013) 15694-15697. doi:10.1021/ja407393y.

[12] A. Kuhn, O. Gerbig, C. Zhu, F. Falkenberg, J. Maier, B. V. Lotsch, A new ultrafast superionic Li-conductor: ion dynamics in $\mathrm{Li}_{11} \mathrm{Si}_{2} \mathrm{PS}_{12}$ and comparison with other tetragonal LGPS-type electrolytes., Phys. Chem. Chem. Phys. 16 (2014) 14669-74. doi:10.1039/c4cp02046d.

[13] Y. Kato, S. Hori, T. Saito, K. Suzuki, M. Hirayama, A. Mitsui, et al., High-power all-solidstate batteries using sulfide superionic conductors, Nat. Energy. (2016) 16030. doi:10.1038/nenergy.2016.30.

[14] J. Maier, Space charge regions in solid two-phase systems and their conduction contributionI. Conductance enhancement in the system ionic conductor-'inert' phase and application on $\mathrm{AgC1}: \mathrm{Al}_{2} \mathrm{O}_{3}$ and $\mathrm{AgC1}: \mathrm{SiO}_{2}$, J. Phys. Chem. Solids. 46 (1985) 309-320. doi:10.1016/00223697(85)90172-6.

[15] C.C. Liang, Conduction characteristics of the lithium iodide-aluminum oxide solid electrolytes, J. Electrochem. Soc. 120 (1973) 1289. doi:10.1149/1.2403248. 
[16] K. Shahi, J.B. Wagner, Ionic conductivity and thermoelectric power of pure and $\mathrm{Al}_{2} \mathrm{O}_{3}$ dispersed AgI, J. Electrochem. Soc. 128 (1981) 6-13.

[17] T. Jow, J.B. Wagner, The effect of dispersed alumina particles on the electrical conductivity of cuprous chloride, J. Electrochem. Soc. 126 (1979) 1963-1972. doi:10.1149/1.2128835.

[18] S. Fujitsu, M. Miyayama, K. Koumoto, H. Yanagida, T. Kanazawa, Enhancement of ionic conduction in $\mathrm{CaF}_{2}$ and $\mathrm{BaF}_{2}$ by dispersion of $\mathrm{Al}_{2} \mathrm{O}_{3}$, J. Mater. Sci. 20 (1985) 2103-2109. doi:10.1007/BF01112293.

[19] P. Knauth, Ionic conductor composites: theory and materials, J. Electroceramics. 5 (2000) 111-125. doi:10.1023/A:1009906101421.

[20] R.C. Agrawal, R.K. Gupta, Superionic solids: composite electrolyte phase - an overview, J. Mater. Sci. 34 (1999) 1131-1162. doi:10.1023/A:1004598902146.

[21] S. Indris, P. Heitjans, H. Eduarde Roman, A. Bunde, Nanocrystalline versus microcrystalline $\mathrm{Li}_{2} \mathrm{O}: \mathrm{B}_{2} \mathrm{O}_{3}$ composites: anomalous ionic conductivities and percolation theory, Phys. Rev. Lett. 84 (2000) 2889-2892. doi:10.1103/PhysRevLett.84.2889.

[22] M.M. Islam, T. Bredow, S. Indris, P. Heitjans, Enhanced conductivity at the interface of $\mathrm{Li}_{2} \mathrm{O}: \mathrm{B}_{2} \mathrm{O}_{3}$ nanocomposites: Atomistic models, Phys. Rev. Lett. 99 (2007). doi:10.1103/PhysRevLett.99.145502.

[23] A. Mei, X.L. Wang, Y.C. Feng, S.J. Zhao, G.J. Li, H.X. Geng, et al., Enhanced ionic transport in lithium lanthanum titanium oxide solid state electrolyte by introducing silica, Solid. State. Ion. 179 (2008) 2255-2259. doi:10.1016/j.ssi.2008.08.013.

[24] B. Zhu, Z.H. Lai, B.E. Mellander, Structure and ionic conductivity of lithium sulphate aluminum oxide ceramics, Solid. State. Ion. 70-71 (1994) 125-129. doi:10.1016/0167- 
2738(94)90296-8.

[25] H.E. Roman, A. Bunde, W. Dieterich, Conductivity of dispersed ionic conductors: a percolation model with two critical points, Phys. Rev. B. 34 (1986) 3439-3445.

[26] E.R. Roman, M. Yussouff, Particle-size effect on the conductivity of dispersed ionic conductors, Phys. Rev. B. 36 (1987) 7285-7288. doi:10.1017/CBO9781107415324.004.

[27] H.E. Roman, A continuum percolation model for dispersed ionic conductors, J. Phys. Condens. Matter. 2 (1990) 3909-3917. doi:10.1088/0953-8984/2/17/002.

[28] D. Wohlmuth, V. Epp, B. Stanje, A.-M. Welsch, H. Behrens, M. Wilkening, High-energy mechanical treatment boosts ion transport in nanocrystalline $\mathrm{Li}_{2} \mathrm{~B}_{4} \mathrm{O}_{7}$, J. Am. Ceram. Soc. 9 (2016) 1687-1693. doi:10.1111/jace.14165.

[29] B.S.R. Sastry, F.A. Hummel, Studies in Lithium Oxide Systems: V, $\mathrm{Li}_{2} \mathrm{O}-\mathrm{B}_{2} \mathrm{O}_{3} \cdot \mathrm{B}_{2} \mathrm{O}_{3}$, J. Am. Ceram. Soc. 41 (1958) 7-17. doi:10.1111/j.1151-2916.1958.tb13496.x.

[30] B.S.R. Sastry, F.A. Hummel, Studies in Lithium Oxide Systems: VII, $\mathrm{Li}_{2} \mathrm{O}-\mathrm{B}_{2} \mathrm{O}_{3}-\mathrm{SiO}_{2}, \mathrm{~J}$. Am. Ceram. Soc. 43 (1960) 23-33.

[31] R. Blender, W. Dieterich, A random AC network model for dispersed ionic conductors, J. Phys. C. 20 (1987) 6113-6126. doi:10.1088/0022-3719/20/36/013.

[32] A.G. Rojo, H.E. Roman, Effective-medium approach for the conductivity of dispersed ionic conductors, Phys. Rev. B . 37 (1988) 3696-3698. doi:10.1017/CBO9781107415324.004.

[33] I.D. Raistrick, D.R. Franceschetti, J.R. Macdonald, The Electrical Analogs of Physical and Chemical Processes, in: Impedance Spectroscopy: Theory, Experiment, and Applications, 2005: pp. 72-74. 
[34] N. Bonanos, B.C.H. Steele, E.P. Butler, Characterization of Materials, in: E. Barsoukov, J.R. Macdonald (Eds.), Impedance Spectroscopy: Theory, Experiment, and Applications, 2nd ed., Wiley, 2005: pp. 213-214.

[35] S. Guangling, Equivalent circuit model for AC electrochemical impedance spectroscopy of concrete, Cem. Concr. Res. 30 (2000) 1723-1730. doi:10.1016/S0008-8846(00)00400-2.

[36] B.J. Christensen, T. Coverdale, R. A. Olson, S.J. Ford, E.J. Garboczi, H.M. Jennings, et al., Impedance spectroscopy of hydrating cement-based materials: measurement, interpretation, and application, J. Am. Ceram. Soc. 77 (1994) 2789-2804. doi:10.1111/j.11512916.1994.tb04507.x.

[37] S. Kim, J. Fleig, J. Maier, Space charge conduction: simple analytical solutions for ionic and mixed conductors and application to nanocrystalline ceria, Phys. Chem. Chem. Phys. 5 (2003) 2268-2273. doi:10.1039/B300170A.

[38] J. Jamnik, Treatment of the impedance of mixed conductors equivalent circuit model and explicit approximate solutions, J. Electrochem. Soc. 146 (1999) 4183. doi:10.1149/1.1392611.

[39] D.R. Franceschetti, J.R. Macdonald, Electrode kinetics, equivalent circuits, and system characterization: small-signal conditions, J. Electroanal. Chem. Interfacial. Electrochem. 82 (1977) 271-301. doi:10.1016/S0022-0728(77)80262-3.

[40] H. Fricke, XXXIII. The theory of electrolytic polarization, Philos. Mag. Ser. 7. 14 (1932) 310-318. doi:10.1080/14786443209462064.

[41] H. Fricke, The Maxwell-Wagner dispersion in a suspension of ellipsoids, J. Phys. Chem. 57 (1953) 934-937. doi:10.1021/j150510a018. 
[42] I.D. Raistrick, C. Ho, R.A. Huggins, Ionic conductivity of some lithium silicates and aluminosilicates, J. Electrochem. Soc. 123 (1976) 1469-1476. doi:10.1149/1.2132621.

[43] D.P. Button, L.S. Mason, H.L. Tuller, D.R. Uhlmann, Structural disorder and enhanced ion transport in amorphous conductors, Solid. State. Ion. 9-10 (1983) 585-592. doi:10.1016/0167-2738(83)90299-0.

[44] M.M.E. Jacob, S. Rajendran, R. Gangadharan, M.S. Michael, S.R.S. Prabaharan, Effect of dispersion of $\mathrm{CeO}_{2}$ in the ionic conductivity of $\mathrm{Li}_{2} \mathrm{MnCl}_{4}$, Solid. State. Ion. 86-88 (1996) 595-602. doi:10.1016/0167-2738(96)00214-7.

[45] M.N.T. Nishino, Fabrication of $\mathrm{Li}_{3} \mathrm{PO}_{4}-\mathrm{Al}_{2} \mathrm{O}_{3}$ composites by an electrochemical technique, Solid. State. Ion. 70/71 (1994) 96-100.

\section{Figures Captions}

Fig. 1 Fabrication steps for the lithium borate/silica glass-ceramics. Temperatures within each step correspond to peak temperatures of the heat treatments. $* 550{ }^{\circ} \mathrm{C}$ sintering followed by sputtering was done with $\mathrm{x}=0.33$ nanoscale-S sample only.

Fig. $2 \mathrm{XRD}$ patterns for samples with ratio $R=0.5$ or $\mathrm{x}=0.33\left(\bullet-\mathrm{Li}_{2} \mathrm{~B}_{4} \mathrm{O}_{7} ; \boldsymbol{\Delta}-\mathrm{SiO}_{2} ; \star-\right.$ $\mathrm{Ag})$.

Fig. 3 Location of synthesized lithium borate/silica composites in an equilibrium ternary phase diagram for $x=0.50$ and $x=0.33$. Note that the phase diagram is reported in weight percent [30].

Fig. 4 XRD patterns for samples with ratio $R=1.0$ or $\mathrm{x}=0.50\left(\bullet-\mathrm{Li}_{2} \mathrm{~B}_{4} \mathrm{O}_{7} ; \boldsymbol{\Delta}-\mathrm{SiO}_{2} ; \star-\right.$ $\left.\mathrm{Ag} ; \bullet-\mathrm{Li}_{2} \mathrm{Si}_{2} \mathrm{O}_{5} ;-\mathrm{Li}_{2} \mathrm{SO}_{3} ; \boldsymbol{\nabla}-\mathrm{LiBO}_{2}\right)$.

Fig. 5 SEM images of $\mathrm{x}=0.33$ nanoscale (left) and $\mathrm{x}=0.33$ micron (right) polished crosssections. Lighter region is the silica rich phase while the darker region is the lithium borate rich phase. Numberings on SEM images correspond to the sample point EDS spectra in Fig. 6. 
Fig. 6 Sample of compiled EDS spectra for $\mathrm{x}=0.33$ nanoscale and micron samples. For the nanoscale sample, the phases were homogeneously distributed making EDS point spectra vary widely. Hence, an almost identical elemental distribution for two different regions can be observed. Meanwhile, the micron samples gave a better elucidation of elemental distribution.

Fig. 7 The classical circuit model (2P) for a polycrystalline material. The 2P model has a modification in the grain to account frequency dispersion.

Fig. 8 (a) The brick-layer physical picture, which gives an idea of how the circuit model can be made with dispersed ionic conductor assumptions and microstructure. (b) The physical circuit model, which provides a way to break down the brick-layer physical picture into the series and parallel configuration. In the series configuration, transport contribution is divided into an effective mean grain impedance and effective mean grain boundary impedance. Each impedance is a mixture contribution for each phase. In the parallel configuration, transport configuration is dominated by interface pathways partially blocked by amorphous boundaries.

Fig. 9 (a) The final theoretical model (TM). $\left(R_{\text {int }}+Q_{\text {block }}\right)$ represents the parallel configuration while $\left(C_{a l l}{ }^{-1}+\left(R_{g}+\left(R_{g b}{ }^{-1}+C_{g b}{ }^{-1}\right)^{-1}\right)^{-1}\right.$ represents the series configuration. (b) The approximation model (AM). The series configuration is simplified by eliminating $C_{g b}$.

Fig. 10 Combined Nyquist, imaginary impedance (-Z") semi-log, and imaginary modulus (M") plot of $\mathrm{x}=0.33$, nanoscale sample at $300{ }^{\circ} \mathrm{C}$. The benchmark $2 \mathrm{P}$ model predicted a large high-frequency M" tail while the TM and AM models captured the relaxation behavior more properly.

Fig. 11 Combined Nyquist, imaginary impedance (-Z") semi-log, and imaginary modulus (M") plot of $\mathrm{x}=0.50$, micron sample at $300{ }^{\circ} \mathrm{C}$. The benchmark $2 \mathrm{P}$ model predicted slightly large high-frequency M" tail instead, creating an asymmetric M" peak.

Fig. 12 (a) Arrhenius plot with the AM model for the nanoscale samples. (b) Arrhenius plot with the AM model also for the micron samples. All samples follow the relationship $E_{\text {all }}>$ $E_{\text {int. }}$

\section{Tables}

\begin{tabular}{|llc|}
\hline Ratio of $\mathrm{n}_{\mathrm{Li}_{2} \mathrm{O}} / \mathrm{n}_{\mathrm{B}_{2} \mathrm{O}_{3}}$ & $R=0.5(\mathrm{x}=0.33)$ & $R=1.0(\mathrm{x}=0.50)$ \\
\hline $\begin{array}{l}\text { Micron batch } \\
\text { 24 h ball-milling, amorphous silica }\end{array}$ & $\mathrm{x}=0.33$ micron & $\mathrm{x}=0.50$ micron \\
\hline $\begin{array}{l}\text { Nanoscale batch } \\
\text { 8 h planetary milling, amorphous nanosilica }\end{array}$ & $\begin{array}{l}\mathrm{x}=0.33 \text { nanoscale } \\
\mathrm{x}=0.33 \text { nanoscale-S }\end{array}$ \\
\hline
\end{tabular}


Table 1 Naming conventions for the lithium boratelsilica samples. All samples undergo identical ceramic fabrication process as prescribed in Fig. 1. Optimization is based on size reduction principle. *a variant named $\mathrm{x}=0.33$, nanoscale-S was created by sintering the sample at $550{ }^{\circ} \mathrm{C}$ and sputtering the $\mathrm{Ag}$ electrode instead of co-firing.

\begin{tabular}{|lll|}
\hline Parameters $(2 \mathrm{P})$ & $\begin{array}{l}\mathrm{x}=0.33 \text { nanoscale } \\
300{ }^{\circ} \mathrm{C}\end{array}$ & $\begin{array}{l}\mathrm{X}=0.50 \text { micron } \\
300{ }^{\circ} \mathrm{C}\end{array}$ \\
\hline$R_{g}(\mathrm{M} \Omega)$ & $1.29 \pm 0.03$ & $3.93 \pm 0.04$ \\
\hline$C_{g}(\mathrm{pF})$ & $2.01 \pm 0.03$ & $3.42 \pm 0.04$ \\
\hline$Q_{g}\left(\mathrm{nF} \mathrm{s}^{(1-\mathrm{n})}\right)$ & $0.51 \pm 0.06$ & $0.92 \pm 0.06$ \\
\hline$n$ & $0.64 \pm 0.01$ & $0.53 \pm 0.01$ \\
\hline$R_{g b}(\mathrm{M} \Omega)$ & $0.35 \pm 0.02$ & $0.52 \pm 0.03$ \\
\hline$C_{g b}(\mathrm{nF})$ & $0.14 \pm 0.01$ & $0.45 \pm 0.03$ \\
\hline
\end{tabular}

Table 2 Fitted 2P model parameters for each micron sample.

\begin{tabular}{|lll|}
\hline Parameters $(\mathrm{TM})$ & $\begin{array}{l}\mathrm{x}=0.33 \text { nanoscale } \\
300{ }^{\circ} \mathrm{C}\end{array}$ & $\begin{array}{l}\mathrm{x}=0.50 \text { micron } \\
300{ }^{\circ} \mathrm{C}\end{array}$ \\
\hline$R_{g}(\mathrm{M} \Omega)$ & $1.38 \pm 0.02$ & $3.91 \pm 0.03$ \\
\hline$R_{g b}(\mathrm{M} \Omega)$ & $0.25 \pm 0.02$ & $0.50 \pm 0.02$ \\
\hline$R_{\text {int }}(\mathrm{M} \Omega)$ & $0.28 \pm 0.02$ & $0.80 \pm 0.04$ \\
\hline$Q_{\text {block }}\left(\mathrm{nF} \mathrm{s}{ }^{(1-\mathrm{n})}\right)$ & $0.18 \pm 0.02$ & $0.41 \pm 0.03$ \\
\hline$n$ & $0.71 \pm 0.01$ & $0.61 \pm 0.01$ \\
\hline$C_{g b}(\mathrm{nF})$ & $0.14 \pm 0.02$ & $0.39 \pm 0.03$ \\
\hline$C_{a l l}(\mathrm{pF})$ & $5.47 \pm 0.05$ & $4.14 \pm 0.02$ \\
\hline
\end{tabular}

Table 3 Fitted TM model parameters for each nanoscale sample.

Notice that $R_{g}>R_{g b}$ and $R_{g}>R_{\text {int }}$. 


\begin{tabular}{|lll|}
\hline Parameters $(\mathrm{AM})$ & $\begin{array}{l}\mathrm{x}=0.33 \text { nanoscale } \\
300{ }^{\circ} \mathrm{C}\end{array}$ & $\begin{array}{l}\mathrm{x}=0.50 \text { micron } \\
300{ }^{\circ} \mathrm{C}\end{array}$ \\
\hline$R_{\text {all }}(\mathrm{M} \Omega)$ & $1.65 \pm 0.02$ & $4.49 \pm 0.02$ \\
\hline$R_{\text {int }}(\mathrm{M} \Omega)$ & $0.29 \pm 0.02$ & $0.79 \pm 0.06$ \\
\hline$Q_{\text {block }}\left(\mathrm{nF} \mathrm{s}^{(1-\mathrm{n})}\right)$ & $0.34 \pm 0.03$ & $0.76 \pm 0.05$ \\
\hline$n$ & $0.67 \pm 0.01$ & $0.56 \pm 0.01$ \\
\hline$C_{\text {all }}(\mathrm{pF})$ & $5.57 \pm 0.06$ & $4.19 \pm 0.04$ \\
\hline
\end{tabular}

Table 4 Fitted AM model parameters for each nanoscale sample.

Notice that $R_{\text {all }}>R_{\text {int }}$.

\begin{tabular}{|llrrl|}
\hline Samples & $\mathrm{T}(\mathrm{K})$ & $\sigma_{\text {all }}\left(\mathrm{S} \mathrm{cm}^{-1}\right)$ & $\sigma_{\text {int }}\left(\mathrm{S} \mathrm{cm}^{-1}\right)$ & Ratio (nanoscale/micron) \\
\cline { 1 - 4 } $\mathrm{x}=0.33$ micron & 673 & $3.01 \cdot 10^{-8}$ & $2.13 \cdot 10^{-7}$ & \multirow{2}{*}{$45\left(\right.$ for $\left.\sigma_{\text {all }}\right) ; 6\left(\right.$ for $\left.\sigma_{\text {int }}\right)$} \\
\hline $\mathrm{x}=0.33$ nanoscale & 673 & $1.35 \cdot 10^{-6}$ & $1.23 \cdot 10^{-6}$ & \\
\cline { 1 - 4 } $\mathrm{x}=0.50$ micron & 573 & $6.11 \cdot 10^{-8}$ & $4.81 \cdot 10^{-7}$ & \multirow{2}{*}{$23\left(\right.$ for $\left.\sigma_{\text {all }}\right) ; 8\left(\right.$ for $\left.\sigma_{\text {int }}\right)$} \\
\hline $\mathrm{x}=0.50$ nanoscale & 573 & $1.44 \cdot 10^{-6}$ & $4.01 \cdot 10^{-6}$ & \\
\hline
\end{tabular}

Table 5 Conductivity values for the combined grain and grain boundary $\left(\sigma_{\text {all }}\right)$ and insulator/conductor interface $\left(\sigma_{\text {int }}\right)$.

\begin{tabular}{|c|c|c|c|c|}
\hline Li-ion Conductors & \multicolumn{4}{|c|}{$E_{a}(\mathrm{eV}) \sigma\left(\mathrm{S} \mathrm{cm}^{-1}\right) \mathrm{T}(\mathrm{K}) \operatorname{Ref}$} \\
\hline $\mathrm{Li}_{2} \mathrm{Si}_{2} \mathrm{O}_{5}$, crystalline & 1.37 & $6.8 \cdot 10^{-8}$ & 673 & [42] \\
\hline $\mathrm{Li}_{2} \mathrm{SiO}_{3}$, crystalline & 0.92 & $3.0 \cdot 10^{-6}$ & 673 & [42] \\
\hline $\mathrm{LiBO}_{2}$, crystalline & 1.37 & $2.4 \cdot 10^{-9}$ & 573 & [43] \\
\hline $\mathrm{LiBO}_{2}\left(0.50 \cdot \mathrm{Li}_{2} \mathrm{O}-0.50 \cdot \mathrm{B}_{2} \mathrm{O}_{3}\right)$, amorphous & 0.49 & $8.6 \cdot 10^{-4}$ & 573 & [43] \\
\hline $\mathrm{Li}_{2} \mathrm{~B}_{2} \mathrm{O}_{7}$, crystalline & 1.18 & $5.8 \cdot 10^{-7}$ & 673 & [43] \\
\hline $\mathrm{Li}_{2} \mathrm{~B}_{2} \mathrm{O}_{7}\left(0.33 \cdot \mathrm{Li}_{2} \mathrm{O}-0.67 \cdot \mathrm{B}_{2} \mathrm{O}_{3}\right)$, amorphou & 0.69 & $2.6 \cdot 10^{-4}$ & 673 & [43] \\
\hline
\end{tabular}

Table 6 Literature values for activation energies and conductivity values for each phase present in this work's composites. It should be noted that most of the literature activation energies are lower than the calculated $E_{\text {all }}$ but higher than $E_{\text {int }}$.

\begin{tabular}{|lcllll|}
\hline Dispersed Ionic Conductors $E_{a}(\mathrm{eV}) \sigma\left(\mathrm{S} \mathrm{cm}^{-1}\right) \mathrm{T}(\mathrm{K})$ Composition Ref. \\
\hline $\mathrm{LiI}_{-} \mathrm{Al}_{2} \mathrm{O}_{3}$ & 0.43 & $1.00 \cdot 10^{-5}$ & 298 & $33-45 \mathrm{~mol} \%$ & {$[15]$} \\
\hline $\mathrm{Li}_{0.5} \mathrm{La}_{0.5} \mathrm{TiO}_{3}-\mathrm{SiO}_{2}$ & 0.41 & $7.50 \cdot 10^{-5}$ & 303 & $5 \mathrm{vol} \%$ & {$[23]$} \\
\hline $\mathrm{Li}_{2} \mathrm{SO}_{4}-\mathrm{Al}_{2} \mathrm{O}_{3}$ & $1.36^{*}$ & $1.00 \cdot 10^{-2}$ & 773 & $18 \mathrm{~mol} \%$ & {$[24]$} \\
\hline
\end{tabular}




\begin{tabular}{|llllll|}
\hline $\mathrm{Li}_{2} \mathrm{MnCl}_{4}-\mathrm{CeO}_{2}$ & 0.50 & $2.00 \cdot 10^{-3}$ & 473 & $10 \mathrm{~mol} \%$ & [44] \\
\hline $\mathrm{Li}_{3} \mathrm{PO}_{4}-\mathrm{Al}_{2} \mathrm{O}_{3}$ & $1.07 * *$ & $1.00 \cdot 10^{-5}$ & 667 & $48-46$ vol\% & [45] \\
\hline
\end{tabular}

Table 7 Activation energies for various Li-ion dispersed ionic conductors. The literature values agree with the activation energy of the discontinuous interface pathways, which is at $\sim 0.35-0.40 \mathrm{eV}$. The exception to this rule is either due to *presence of proton conduction or **an investigation of only one composition, leaving the optimal concentration undetermined. 

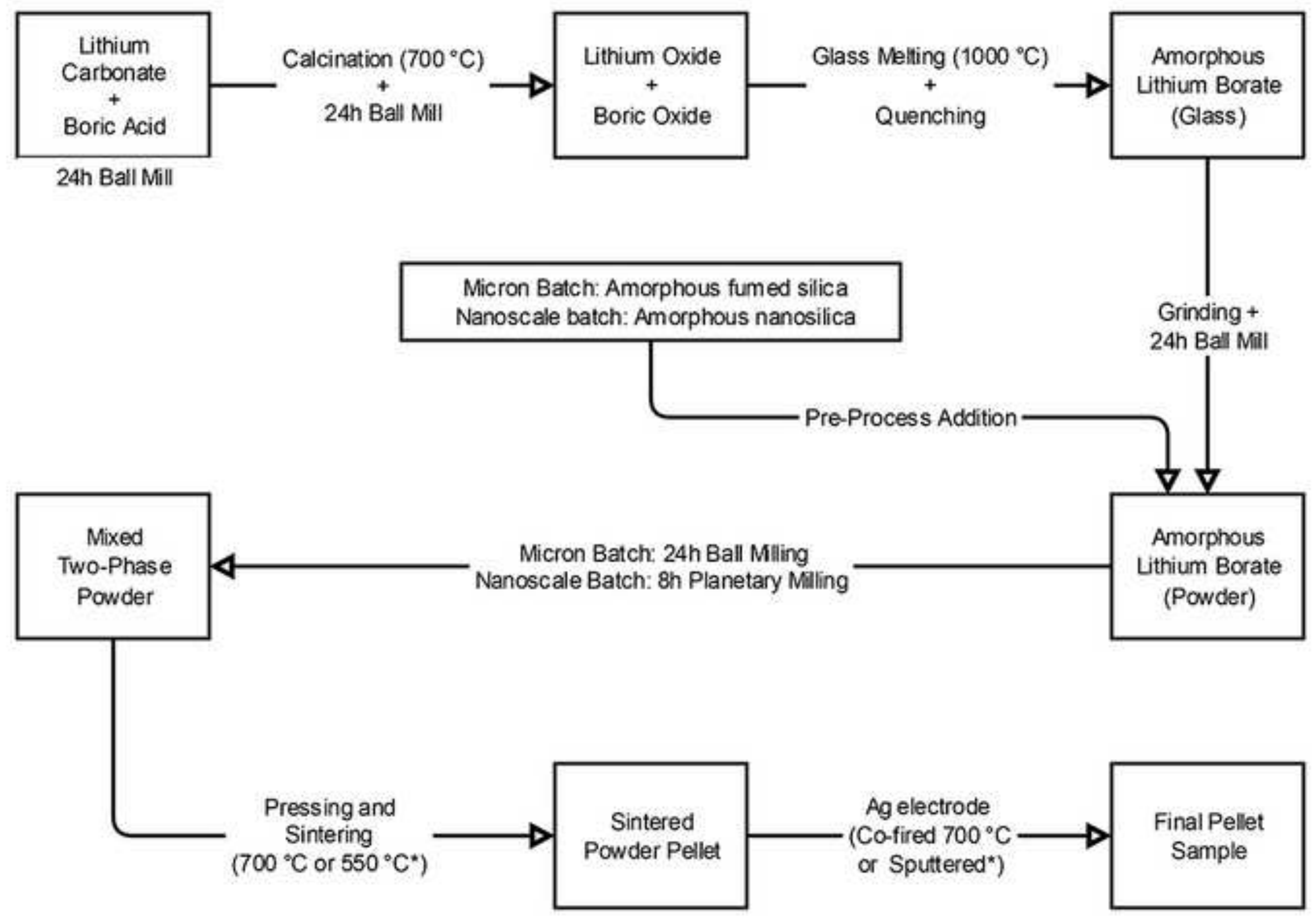


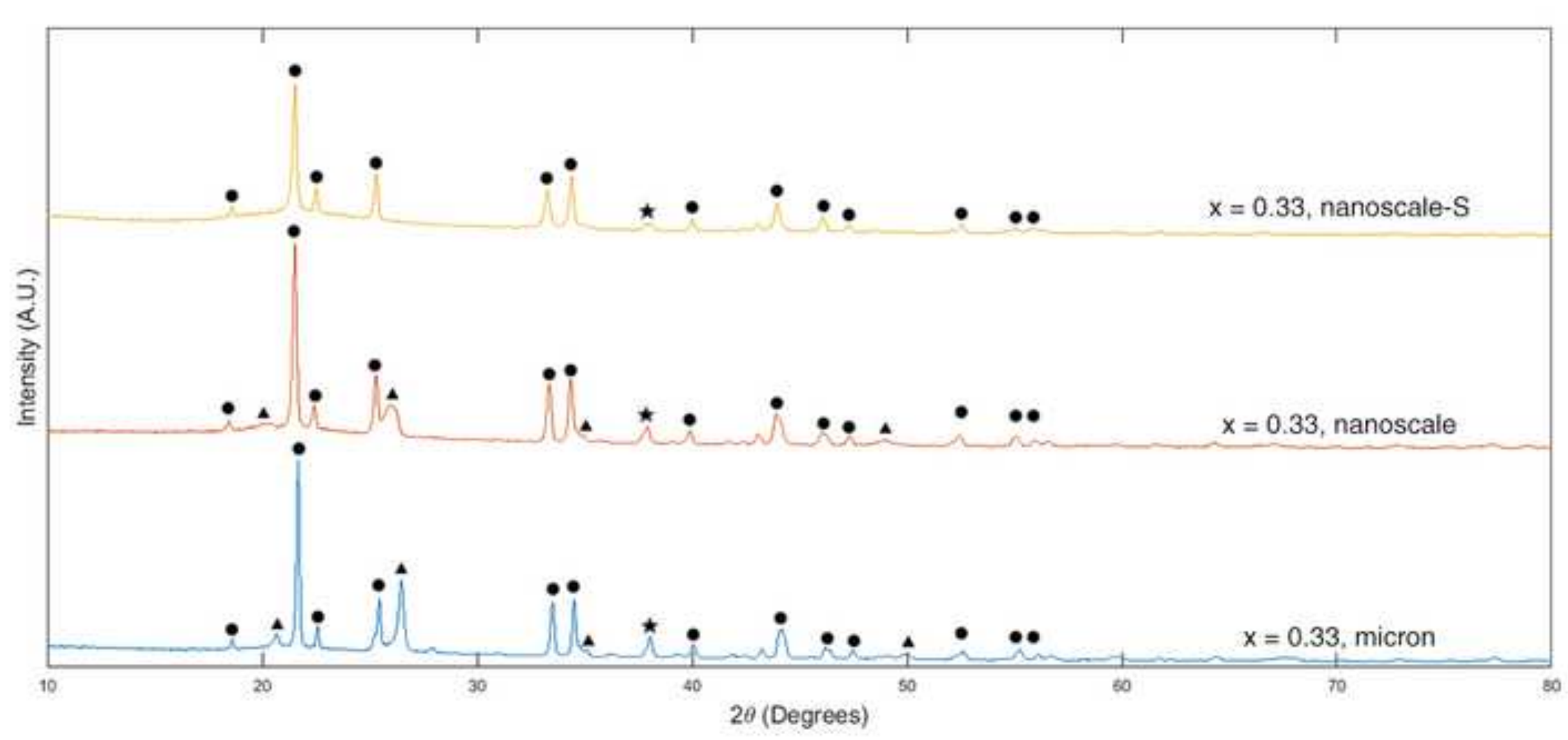

Figure 2 


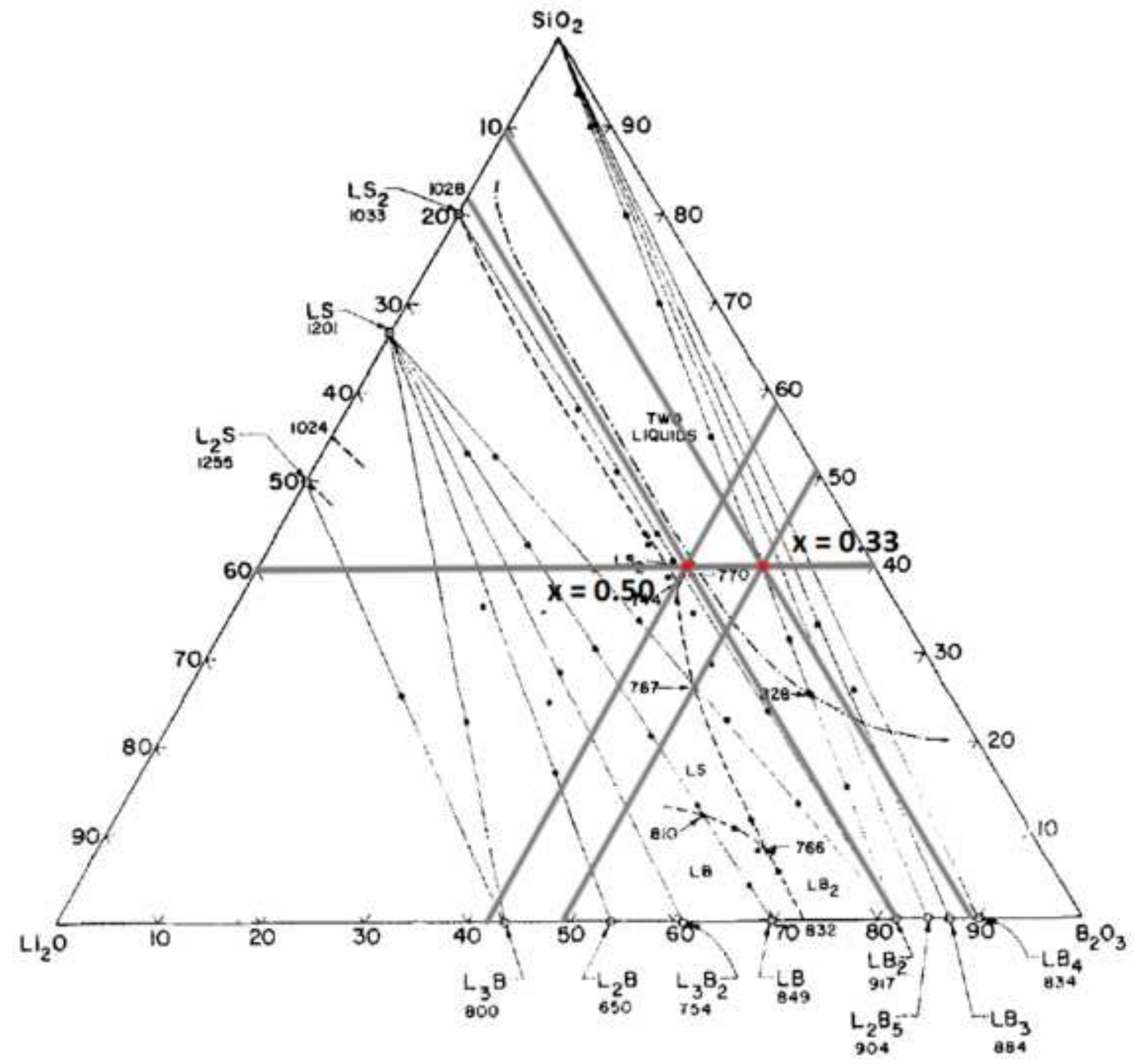




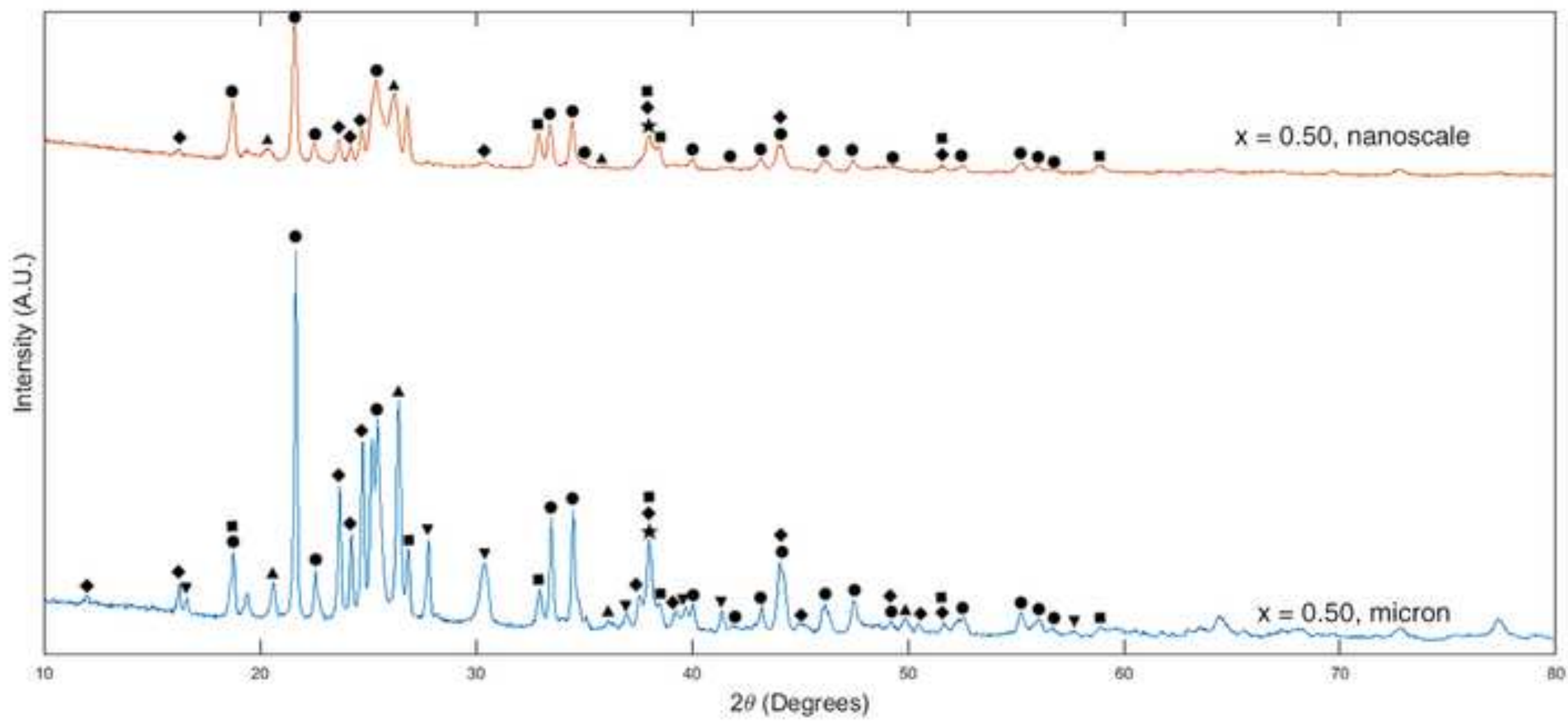



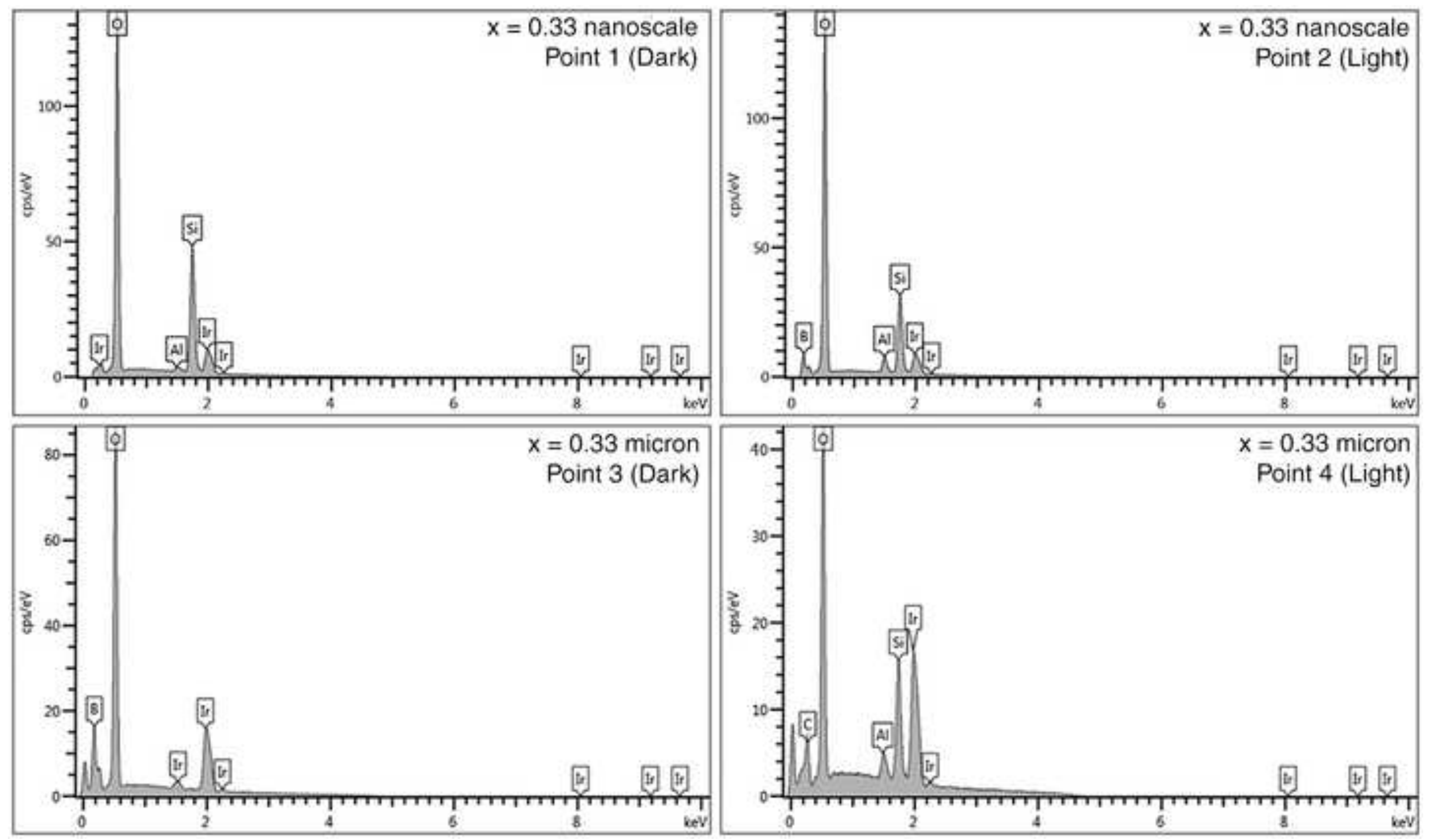


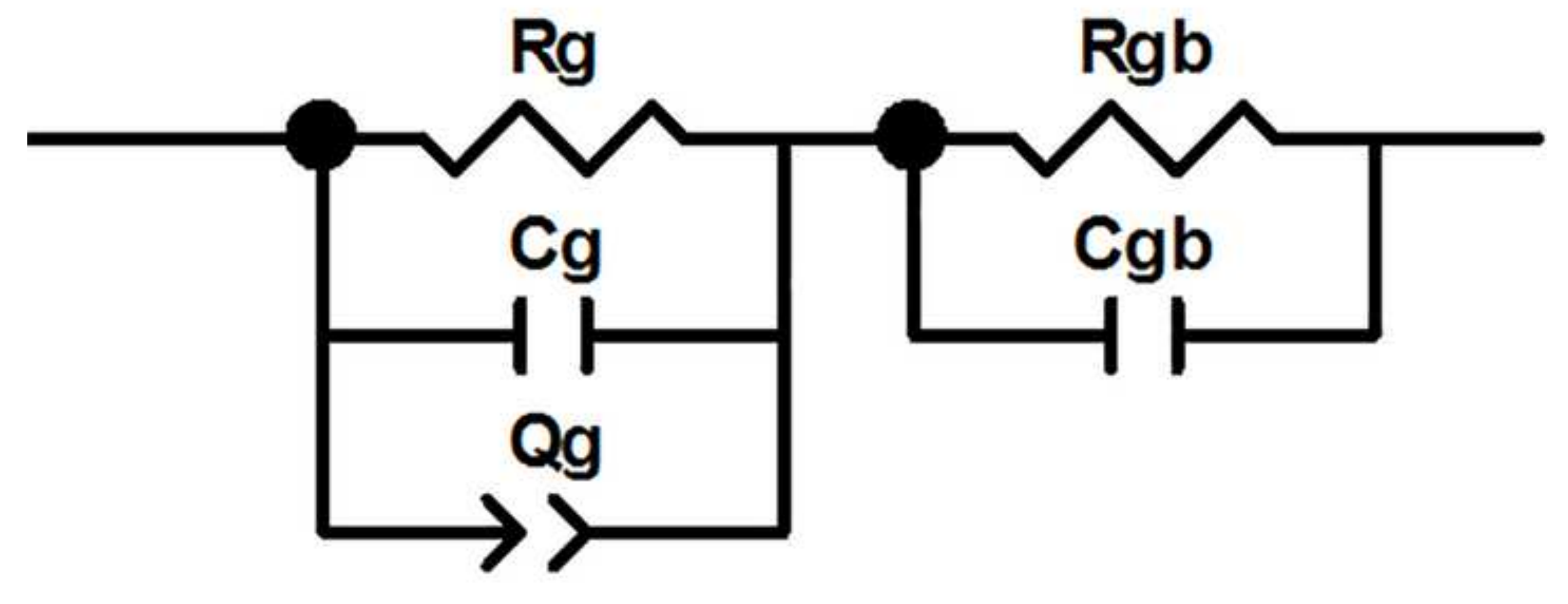

$\mathrm{Cgb}$

.

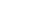

$\mathrm{Rg}$

$\mathrm{Rgb}$

Qg

Figure 
(a) Brick-Layer Physical Picture

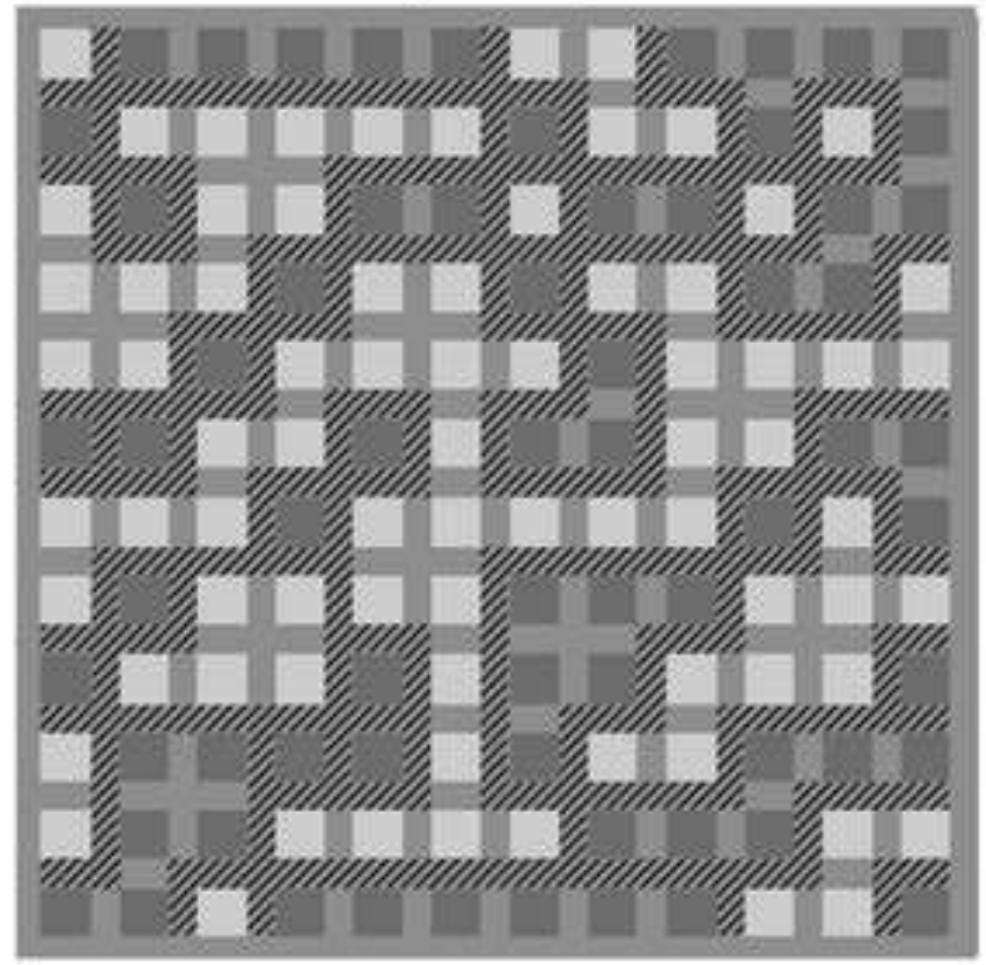

(b) Physical Circuit Model

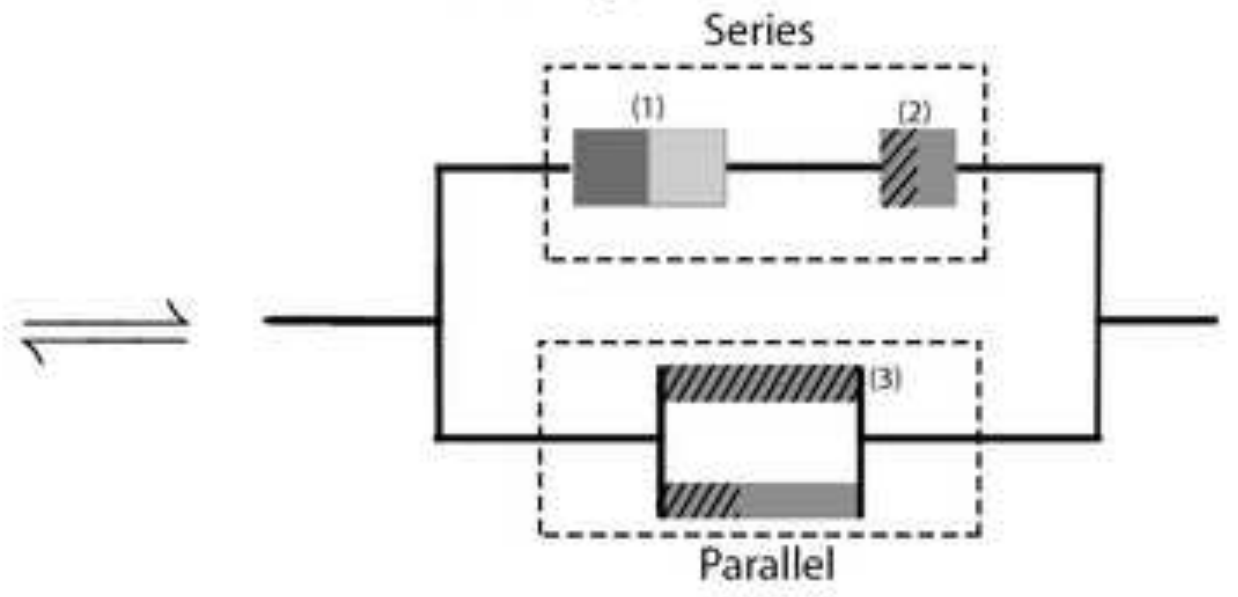

Legend

silica phase

Lithium borate phase

Lithium borate + silica interface

Amorphous boundaries 

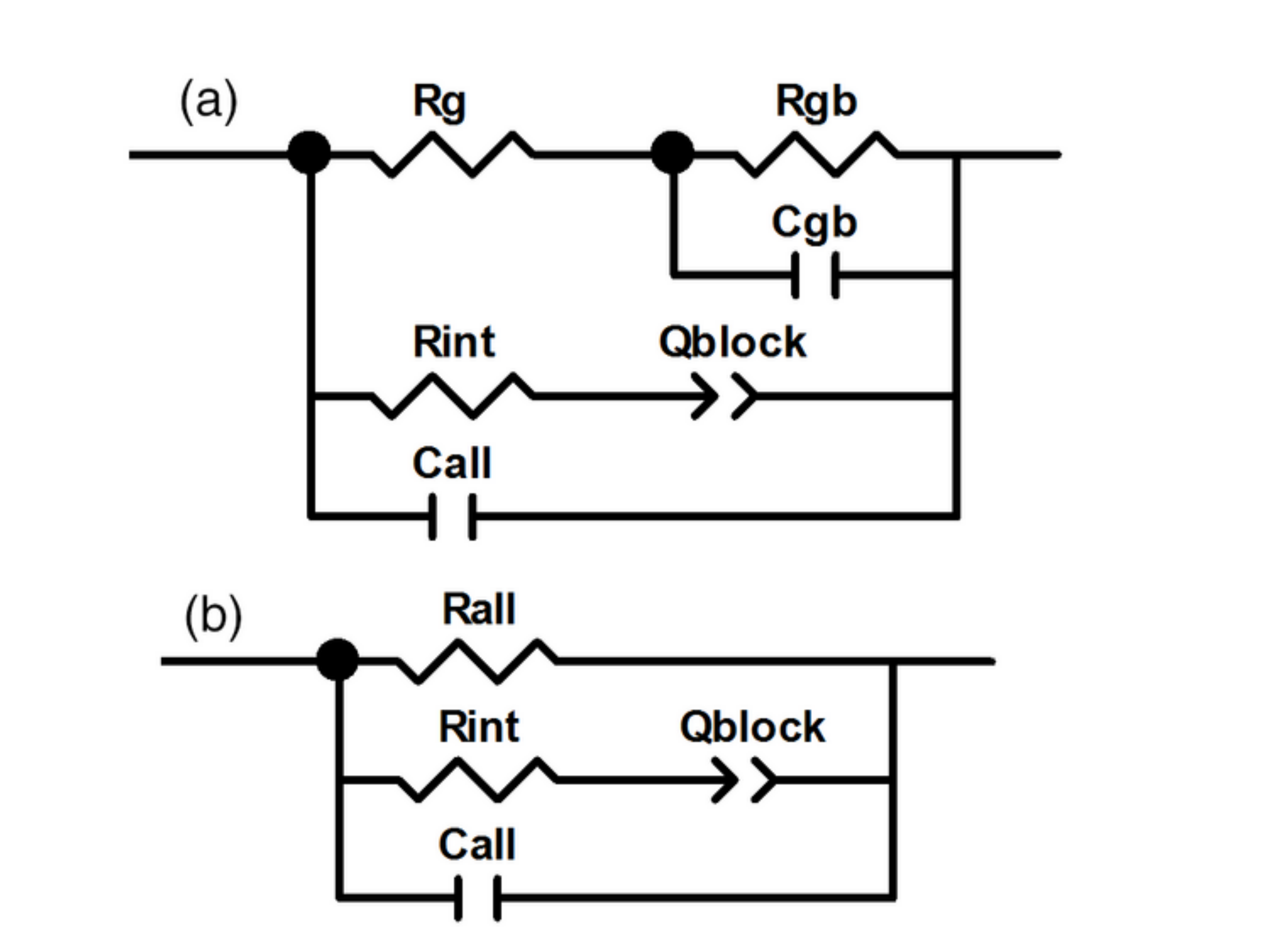

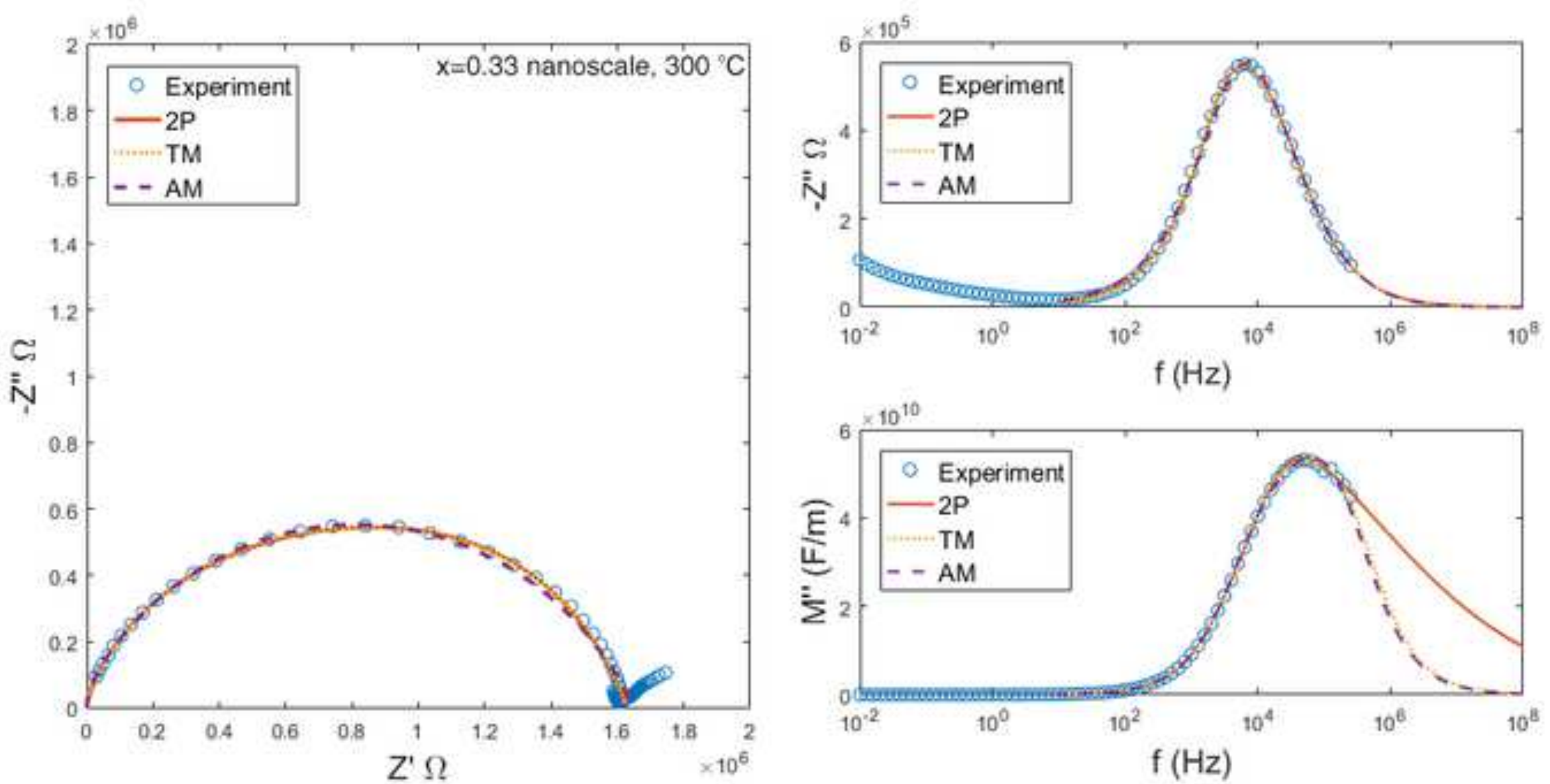

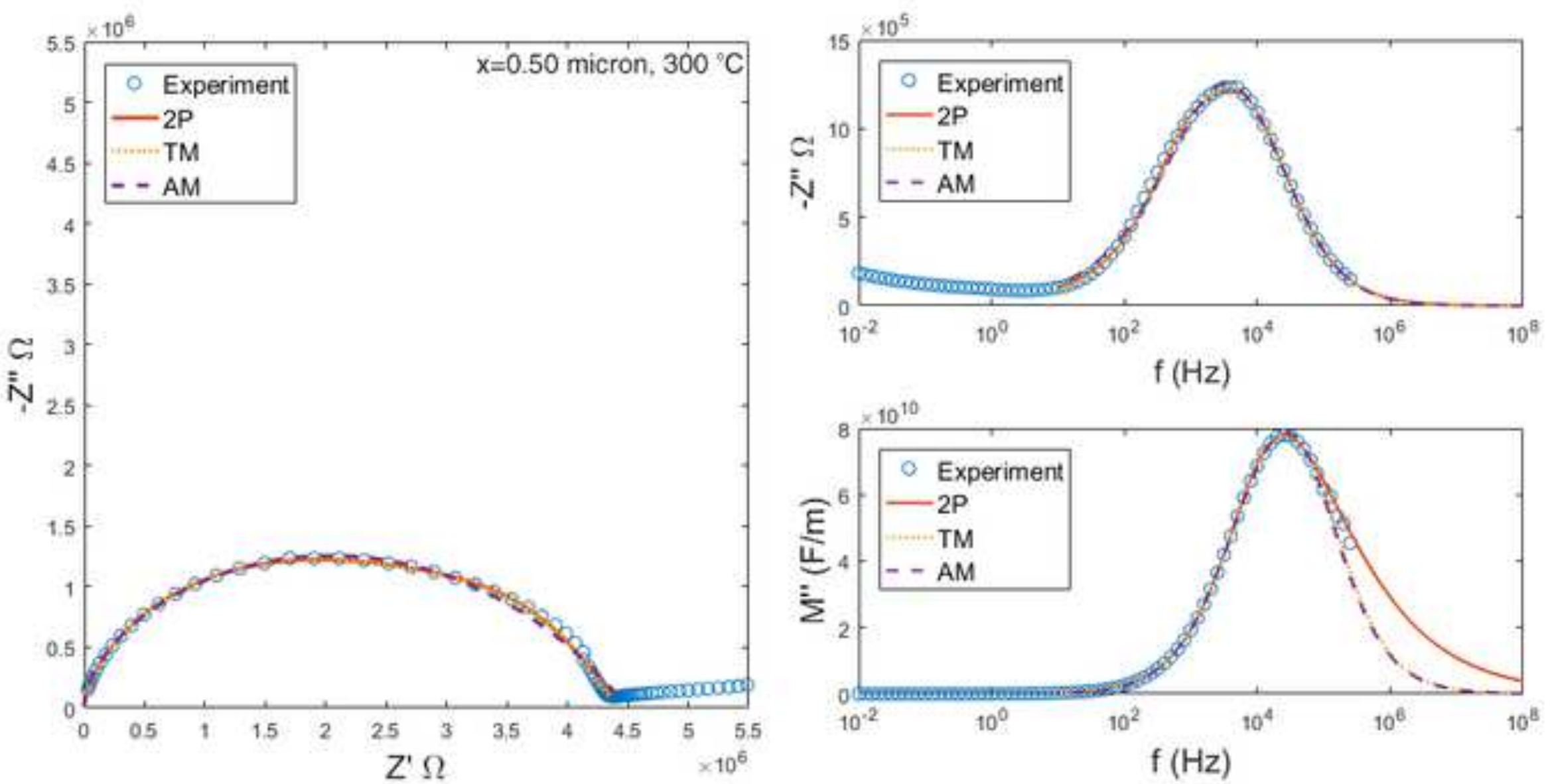
(a)

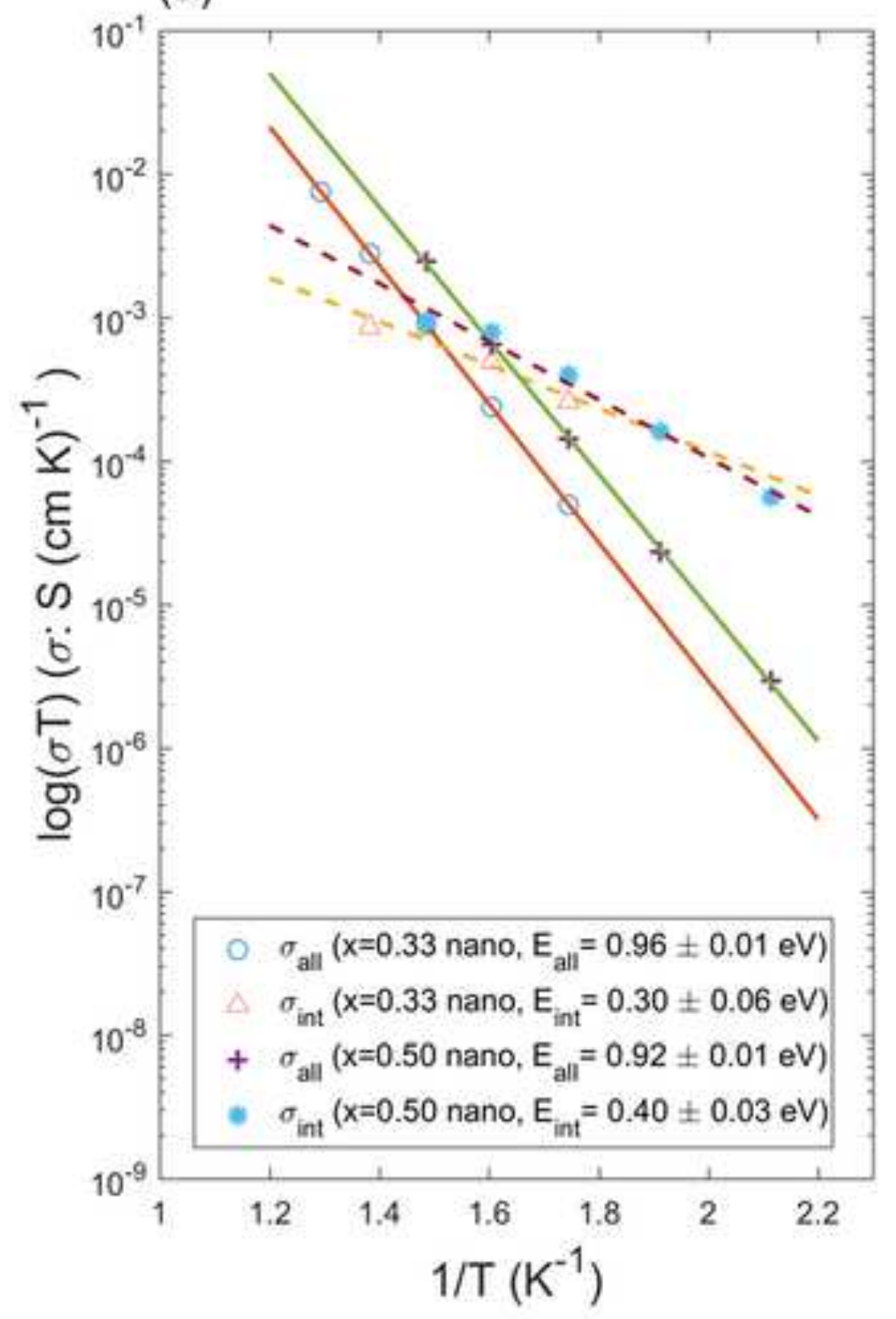

(b)

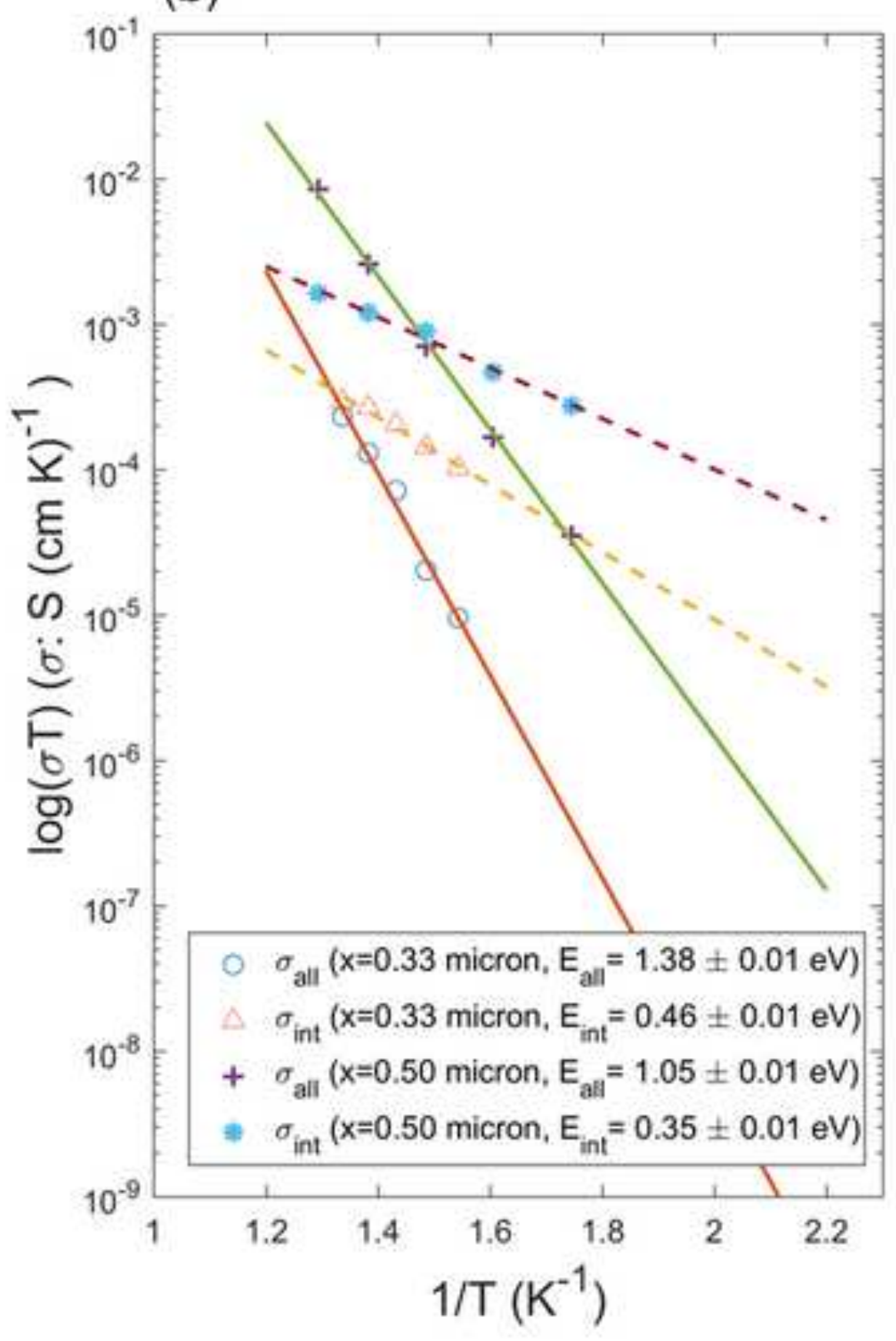

